\title{
NUMBER AGREEMENT IN BRITISH AND AMERICAN ENGLISH: DISAGREEING TO AGREE COLLECTIVELY
}

\author{
KATHRYN BOCK \\ University of Illinois at \\ Urbana-Champaign
}

\section{SALLY ButTERFIELD \\ MRC Cognition and \\ Brain Sciences Unit}

\author{
AnNe CUTLER \\ Max Planck Institute for \\ Psycholinguistics \\ J. COOPER CutTing \\ Illinois State University
}

KATHLEEN M. EBERHARD
University of Notre Dame

KARIN R. HUMPHREYS

McMaster University

\begin{abstract}
British and American speakers exhibit different verb number agreement patterns when sentence subjects have collective head nouns. From linguistic and psycholinguistic accounts of how agreement is implemented, three alternative hypotheses can be derived to explain these differences. The hypotheses involve variations in the representation of notional number, disparities in how notional and grammatical number are used, and inequalities in the grammatical number specifications of collective nouns. We carried out a series of corpus analyses, production experiments, and norming studies to test these hypotheses. The results converge to suggest that British and American speakers are equally sensitive to variations in notional number and implement subjectverb agreement in much the same way, but are likely to differ in the lexical specifications of number for collectives. The findings support a psycholinguistic theory that explains verb and pronoun agreement within a parallel architecture of lexical and syntactic formulation.*
\end{abstract}

A familiar but still striking difference between British and American English is the realization of verb agreement with collective-headed subject noun phrases. The difference is maintained in the usage of speakers and enforced by pronouncements from language watchdogs in the British and American communities. The BBC News Styleguide notes that 'It is the policy of BBC Radio News that collective nouns should be plural, as in The Government have decided' (Allen 2004:31). In American English, the Associated Press Stylebook says 'Nouns that denote a unit take singular verbs and pronouns: class, committee, crowd, family, group, herd, jury, orchestra, team. Some usage examples: The committee is meeting to set its agenda. The jury reached its verdict' (Goldstein 2004:51). Observation reveals contrasting patterns of agreement with the same corporate and collective nouns, as in 1-8, taken verbatim from assorted spoken and written sources (Appendix F lists additional examples).

(1) family

American: I think my family was pretty open-minded about different kinds of people.

British: I don't think the Royal Family are really known for their intelligence.

* Authors are listed alphabetically. The research was supported in part by research and training grants from the National Science Foundation (BNS 90-09611, SBR 94-11627, SBR 98-73450) and the National Institutes of Health (R01-HD21011, R01-MH66089, T32-MH18990), and by visitor stipends from the Max Planck Society. Among the many people who deserve thanks for their help with the collection of data and the interpretation of the results, we mention the most notable: Ellen Bard, Nobuko Chikamatsu, Kirk Hazen, Brian Joseph, Patricia Keyser, Brian Kleiner, Heidi Lorimor, James McQueen, Antje Meyer, Erica Middleton, Elizabeth Octigan, Matthew Rambert, Natasha Warner, and two anonymous referees. Portions of the data have been presented at the meeting of the Psychonomic Society in Vancouver (2003), the conference on Architectures and Mechanisms for Language Processing in Edinburgh (1999), a workshop on Integrative Explanations in the Cognitive Science of Language at Johns Hopkins University (January 2004), and at the University of Edinburgh (February 2001). Correspondence should be directed to the first author. 
(2) government

American: The government [of the Dominican Republic] has reluctantly made some improvements.

British: I understand the pressure that the Israeli government are under.

(3) air traffic control

American: Air traffic control's got us holding.

British: Air traffic control have now given us permission to land.

(4) community

American: ensuring that our community [Santa Monica] does not respond to our financial crisis

British: The British community do not ...

(5) party

American: The party of a man on trial wins the most seats in Parliament.

British: It's clear that this is the reaction of an embattled Tory party that believe it's going to lose.

(6) management

American: Management is not responsible for the street team.

(7) bakery

British: The management are not responsible.

American: Our bakery takes full advantage of ...

British: Our bakery continue to deliver fresh hand made bread.

(8) sports teams

American: The Heat beats the Jazz.

British: Manchester United have completed the signing of a Chinese player.

Many of the British examples strike American speakers as completely unacceptable, even 'awful', to quote one young informant. In a test performed on students from the United States and Britain, samples of British-style collective agreement were corrected by Americans 95 percent of the time, compared to 29 percent by British students (Johansson 1979).

Traditional views of the dialect contrast in both linguistics and psycholinguistics emphasize differences in reliance on number meaning. Quirk and colleagues (1985: 757) state flatly that 'In British English ... collective nouns such as government are often treated as notionally plural'. Vigliocco and Franck (2001:370) echo this, writing that 'British English, in contrast with American English, sometimes allows use of conceptual information rather than syntactic information to compute number agreement' with collective nouns. The explanation given by Quirk and colleagues is that 'the choice between singular or plural verbs depends in British English on whether the group is being considered as a single undivided body, or as a collection of individuals' (1985: 758). The implication is that in American English, speakers are less likely to bring such considerations to bear. Hundt summarizes the consensus about singular agreement as reflecting 'a tendency towards grammatical rather than notional concord' (1998: 80). More formally, Sauerland and Elbourne (2002) proposed that British collective agreement makes use of a Mereology feature, having to do with set formation, that is absent from American English. The traditional view, in short, is that British and American speakers use different kinds of information in agreement.

Taken as an account of how British speakers carry out agreement in the course of normal speaking, these traditional assumptions find a challenge in our work. In this article we develop a contrasting explanation for what American and British speakers 
do differently, examine what the differences imply for accounts of agreement in linguistic and psycholinguistic theories, and experimentally test the competing hypotheses about variations in collective agreement. The major hypotheses have to do with variability in the use of linguistic and nonlinguistic sources of number information in the implementation of agreement.

We first establish the existence and magnitude of the difference between British and American English in the use of plural verbs with collective subjects. Using controlled elicitation, normative ratings, and corpus counts, we then test alternative hypotheses about variations in collective agreement. We consider (i) whether British and American speakers differ in sensitivity to the mereological information provided by discourse or other pragmatic information, (ii) whether they differ in how they use mereological features (Sauerland \& Elbourne 2002) in the implementation of agreement, and (iii) whether the lexical entries of collective nouns differ in the British and American lexicons.

1. Linguistic AND PSYCHOLINGUISTIC APPROACHES TO AGREEMENT. Accounts of agreement in grammatical theory can be broadly divided into constraint-based approaches, such as head-driven phrase structure grammar (HPSG; Pollard \& Sag 1994: Ch. 2, Wechsler \& Zlatić 2003), and derivational approaches, such as minimalism (Chomsky 1995:Ch. 2). The approaches take different stances on two basic questions about agreement. One question is the nature of agreement features, and the other how agreement features are used by the grammar.

On constraint-based accounts, agreement features can have nonlinguistic, cognitive sources which determine the outcome of agreement. Importantly, referential indices provide values for number or gender features, so that whether a phrase is treated as singular or plural is a matter of whether the referent of the phrase is a singleton or an aggregate. A referential index can be called upon not only by noun phrases but also by other sentence constituents that carry feature values, including verbs. One implication is that agreement arises when different clause or discourse constituents use the same referential index to determine their agreement features.

In contrast, agreement features in derivational accounts are formal features represented in and manipulated by the syntax or phonology. In government and binding treatments, the features that enter into agreement relations are represented in clause structure (e.g. Radford 1988:Chs. 6 and 9); in minimalist frameworks, they may be represented as features of logical or phonological form (see den Dikken 2001, Sauerland \& Elbourne 2002). Such features move, or trigger movement, within structural representations. Feature values thus appear where they do because of a formal relationship between the site of an agreement feature and the sites of agreement targets.

1.1. The PSyChOlinguistics of AgREEMENT. Psycholinguistic accounts of agreement split along lines that bear some similarities to those in linguistic theory. Both of the accounts that concern us grow out of theories of language production and deal with how speakers formulate agreement syntax from nonlinguistic sense. Following Fromkin (1971), Garrett (1975, 1988), Bock (1982), Dell (1986), Levelt (1989), and others, the production process begins with a nonlinguistic or prelinguistic MESSAGE, which represents the referential and relational precursors of an utterance, including information potentially relevant to agreement features (such as nonlinguistic number and natural gender). We call these agreement-relevant message features NOTIONAL FEATURES.

Messages are linguistically realized in real-time processes that constitute GRAMMATICAL ENCODING (Levelt 1989). During grammatical encoding, abstract representations of words and morphemes are retrieved, syntactic structures are assembled, and words 
and structures are integrated to create morphologically instantiated representations of utterances that are suitable for phonological encoding.

Major approaches to agreement in psycholinguistic theory are concerned chiefly with processes that originate in message features, link the features to grammatical encoding, and realize the features on agreement targets. Vigliocco and Hartsuiker (2002) sketched an important approach that emphasizes the conceptual underpinnings of agreement processes, which they called MAXIMAL INPUT (with 'maximal' underscoring the contention that conceptual information permeates agreement; Vigliocco \& Franck 2001). In supporting work, Vigliocco and colleagues proposed that the agreement features of controllers and targets have the same sources, within nonlinguistic conceptual representations, but are independently assigned to linguistic constituents and later unified to ensure that their values agree (Vigliocco et al. 1995; Vigliocco, Butterworth, \& Garrett 1996; Vigliocco, Hartsuiker et al. 1996). A related approach emphasizes the constraintsatisfaction nature of agreement, echoing the linguistic account of Pollard and Sag (1994), and asserts the importance of correlations in form and meaning among agreeing elements (Haskell \& MacDonald 2003, Thornton \& MacDonald 2003).

Another view, dubbed MARKING AND MORPHING, identifies two major mechanisms that work together during the implementation of agreement (Bock 2004, Bock et al. 2004, Eberhard et al. 2005). The first mechanism, marking, is related to but more restricted than what is proposed in MAXIMAL INPUT, serving to link linguistically relevant features of nonlinguistic representations to the corresponding linguistic elements. The restriction to corresponding elements means (for example) that the notional referents of arguments determine the feature values of noun phrases in the syntax, and not feature values associated with verb phrases. For a language to directly mark a verb phrase, the notional underpinnings of predicates would have to be evaluated in terms relevant to number or other features (which seems to occur in native North American languages; Durie 1986, Mithun 1988). When the same notional referent happens to control different linguistic constituents, making the constituents coreferential, they should bear the same values of agreement features. Among other things, this mechanism yields agreement between pronouns (including both personal and reflexive pronouns) and their discourse or sentential antecedents, as in anaphoric (Bresnan \& Mchombo 1987) or pragmatic (Wechsler \& Zlatić 2003) agreement. We call agreement that is the product of comarking CONCORD (note that this usage of the term differs from that of Wechsler \& Zlatic 2003).

The second mechanism, morphing, forges the linguistic-structural link between agreement controllers and agreement targets in a derivation-like process. To gain their agreement features, targets must be bound to the linguistic representations of their controllers in the course of grammatical encoding, creating the apparent directionality in agreement that is associated (for instance) with subject-verb agreement in English. The product of morphing is agreement CONTROL.

The workings of this account can be illustrated in terms of antecedent-pronoun and subject-verb number agreement in English (respectively, pronoun and verb number agreement, for short). Pronoun and verb number both originate in message valuations, but they differ in how they come to reflect message-based number valuations. Personal pronouns carry a number with them from the lexicon and their phrases may be marked in the syntax, as well. Normally, when a pronoun is coreferential with another numberbearing noun phrase, the number will be the same because of the normal satisfaction of number semantics that occurs during marking and lexical selection. As described 
above, this constitutes agreement concord. Verb number, in contrast, reflects number valuation only indirectly, because verbs inherit the number of the subject noun phrase during grammatical encoding. This constitutes control of verb number by the subject number.

Psycholinguistic evidence for the workings of marking and morphing was reported for American English in Bock et al. 2004. As in most laboratory work on agreement (e.g. Bock \& Miller 1991, Eberhard 1999, Fayol et al. 1994, Haskell \& MacDonald 2003, Solomon \& Pearlmutter 2004, Vigliocco et al. 1995, Vigliocco, Butterworth, \& Garrett 1996, Vigliocco \& Franck 1999, 2001), Bock et al. 2004 relied on the phenomenon of ATTRACTION (Jespersen 1924) to introduce variability into the realization of agreement. Table 1 gives attested examples of plural attraction for verbs and pronouns from spontaneous speech, broadcast speech, and written sources. In attraction, agreement features from a noun phrase that is not the canonical controller of agreement appear on an agreement target. The noncanonical controller is sometimes called an attractor, an interloper, or a local noun phrase; here we call it an attractor. Grammatically plural attractors are much more potent than singulars, presumably due to plural specification (and the absence of specification for singulars; Eberhard 1997). Note that a similar singular-plural asymmetry is a well-known feature of other nonstandard forms of agreement (Kimball \& Aissen 1971), although there are also documented cases in which any separation between subject and verb leads to increased use of singular verb forms (Hazen 1996, 2000).

In attraction, psycholinguistic evidence suggests that the plural features of attractors migrate to the site from which the agreement features of the controller are normally transmitted to the agreement target, rather than being directly linked to the target. Among other things, the structural depth of an attractor matters more to the likelihood of attraction than linear distance (Bock \& Cutting 1992, Franck et al. 2002, Vigliocco \& Nicol 1998), and the semantic properties of attractors are less important to attraction than the semantic properties of controllers are to agreement (Bock et al. 2001). Other kinds of agreement errors may be more dependent on the meaning of a spurious controller, stemming from predication confusion (cf. Bock \& Miller 1991:experiment 3, Hupet et al. 1998, Thornton \& MacDonald 2003).

SPOKEN ENGLISH

'How much correction of syntactic errors are there, anyway?' (American, 1983)

'The quality of the talks were uniformly high' (American, 1994)

'The increase in processing times are tied ...' (American, 2002)

'I don't think it much matters where the final re-interment of these men are.' (American, 1988)

'the breaking of relations in themselves' (American, 1989)

'and considering what the function of humorous statements are in conversation ...' (American, 1984)

'I'm not sure how meaningful the idea of pronunciation rules are' (British, 1982)

'what the system controlling the eyes are doing' (British, 1984)

WRITTEN ENGLISH

'At first, membership in these unions were voluntary' (American, 1990)

'Good grammar that is favorable to listeners are often associated with people from an upper class' (American, 1992)

'Closing these gaps are a priority for NIMH' (American, APS Monitor, September 2000, p. 14)

'the distribution of clean needles and condoms are the solution' (American, Republican party platform, 1992, p. 26)

'his success playing comic strip (and cosmic strip) characters have made him' (British, Sunday Times [of London] Magazine, 26 May 1985, p. 25)

'her personal collection of more than 200 paste, glass, gilt, silk thread, enamel and simulated gem-stone encrusted pieces were put up for auction' (British, Sunday Times [of London], 8 November 1987)

TABLE 1. Observed instances of apparent plural attraction in spoken and written American and British English. 
In their work, Bock and colleagues (2004) relied on the elicitation of sentence completions that contained finite verbs or tag pronouns. The controllers of the verbs and the antecedents of the pronouns were subject noun phrases contained in so-called preambles that speakers produced aloud and then completed. Crucially, the same noun phrases served as the subjects of verbs and the antecedents for pronouns, and across conditions they varied in different ways in number meaning and number morphology. The variations are illustrated in Table 2. Different experiments were designed to examine the effects of variations in notional number that cooperated or competed with the conventional grammatical number of the subject (and antecedent) noun phrases.

\begin{tabular}{|c|c|c|c|}
\hline & NUMBER OF & NUMBER OF & SAMPLE VERB CONTROLLER/ \\
\hline EXPERIMENTAL MANIPULATION & HEAD NOUN & ATTRACTOR & PRONOUN ANTECEDENT \\
\hline \multirow{4}{*}{$\begin{array}{l}\text { 1. Grammatical number of head } \\
\text { and attractor }\end{array}$} & Singular & Singular & The key to the cabinet \\
\hline & Singular & Plural & The key to the cabinets \\
\hline & Plural & Singular & The keys to the cabinet \\
\hline & Plural & Plural & The keys to the cabinets \\
\hline \multirow{4}{*}{$\begin{array}{l}\text { 2. Collective vs. individual } \\
\text { attractors } \\
\text { 3. Collective vs. individual } \\
\text { heads }\end{array}$} & Singular & Singular & The record of the team/player \\
\hline & Singular & Plural & The record of the teams/players \\
\hline & Singular & Singular & $\begin{array}{l}\text { The team/player with the } \\
\text { commercial contract }\end{array}$ \\
\hline & Singular & Plural & $\begin{array}{l}\text { The team/player with the } \\
\text { commercial contracts }\end{array}$ \\
\hline \multirow{2}{*}{$\begin{array}{l}\text { 4. Notionally singleton and } \\
\text { distributed senses }\end{array}$} & Singular & Plural & The letter from the lawyers \\
\hline & Singular & Plural & The picture on the postcards \\
\hline $\begin{array}{l}\text { 5. Variable vs. invariable plural } \\
\text { attractors }\end{array}$ & Singular & Plural & $\begin{array}{l}\text { The drawer for the needles/ } \\
\text { tweezers }\end{array}$ \\
\hline
\end{tabular}

TABLE 2. Sample subject noun phrases and pronoun antecedents from Bock et al. 2004.

Consistent with the marking-and-morphing account of the mechanisms behind concord and control, pronouns were substantially more likely than verbs to display a grammatical number that accorded with notional properties of the subject noun phrase (see also Hundt 1998). Although verbs, too, were sensitive to notional number properties, pronouns were much more so (see also Bock et al. 1999). The marking-and-morphing account of this difference is in terms of the direct bequest to the nominal elements involved in concord (noun phrases and pronouns) of the number meaning of their nonlinguistic referents, compared to the indirect, linguistically mediated control relationship between grammatical number features of linguistic controllers and targets (subjects and verbs).

These agreement results are consistent with longstanding observations about differences between verbs and pronouns in sensitivity to notional number (e.g. as codified in Corbett's AGREEMENT HIERARCHY $(1979,2000)$, with its associations to the ANIMACY HIERARCHY (Comrie 1981, Smith-Stark 1974; see also Joosten et al. 2006). But going beyond the agreement hierarchy, this was a key dissociation in the behavior of verbs and pronouns with respect to agreement and attraction. Though pronouns were much more likely than verbs to convey notional number in agreement, in attraction they were no more likely than verbs to convey the notional number properties of attractors. Indeed, like verbs, they appeared to be sensitive only to the grammatical properties of the attractors. In the marking-and-morphing account, this result is ascribed to the normal workings of agreement control, taken to be the transmission of agreement features from a controller to a target. In attraction, the features of the controller are disrupted or displaced by those of the attractor, and in their stead, the attractor's features are transferred to the target. 
This similarity between verbs and pronouns in attraction serves to rule out several alternative accounts of the difference between them in agreement. First, verbs and pronouns typically differ in their structural and linear positions with respect to their putative controllers or antecedents. These distributional variations on their own have been seen as creating differences in sensitivity to notional number: in grammatical gender languages, it is often observed that the likelihood of grammatical gender agreement between pronouns and their antecedents decreases with increasing distance (Drosdowski 1984). In attraction, however, there is no difference between verbs and pronouns in sensitivity to notional number, even though the same relative differences in distance hold in attraction as in agreement (i.e. verbs tend to be closer to their attractors than pronouns are). In attraction, neither verbs nor pronouns display notional sensitivity, and pronouns occur in different clauses than their attractors without displaying sensitivity to the attractors' notional number (Bock et al. 2004).

Second, the normal difference between verbs and pronouns in notional sensitivity might be attributed to consistent differences in their linguistic nature: verb inflections could be treated as bound elements selected on the basis of grammatical properties and pronouns as free elements selected on the basis of their semantics. However, the vulnerability of pronouns to attraction, and the equality of verbs and pronouns as targets of attraction, suggest that verbs and pronouns are both checked against grammatical agreement properties that are in play in utterances.

The marking-and-morphing account suggests more detailed hypotheses about the nature of the difference between British and American English with respect to collective agreement. Moreover, the account makes specific predictions about how, under alternative hypotheses, British and American agreement should pattern in terms of divergences and convergences between verb and pronoun number in agreement and attraction. The next section sketches the three leading possibilities.

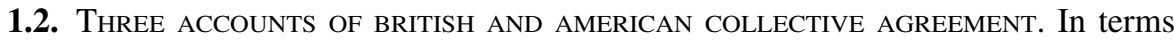
of marking-and-morphing mechanisms, there are three simple ways in which British and American English could come to display different patterns of collective agreement. The first two are psycholinguistically specific versions of the hypothesis that British speakers use the meaning of collectives in a way that differs from American speakers; the third hypothesis is that it is not the meaning but the number specifications of collectives that differ in the two dialects. The three hypotheses involve (i) different resolutions of notional number ambiguity, (ii) different sources of number constraint, and (iii) different lexical specifications, or what is informally called grammatical number.

HyPOTHESIS 1: DIFFERENT RESOLUTIONS OF NOTIONAL AMBIGUITY. The first hypothesis is a version of the traditional view that British collective agreement reflects number semantics. According to hypothesis 1, American collective agreement also reflects number semantics, but a number semantics that is different from British English. So, this view accords well with the maximalist input claim that number meaning permeates agreement. But on this hypothesis, it just so happens that collective meanings differ between American and British English.

Specifically, hypothesis 1 is that the difference between American and British collective agreement is due to different biases about the resolution of ambiguities in collective and distributive senses. Collections of all kinds can be construed either as singleton sets or as aggregations of individuals; even a skeleton can be seen as a set or as an aggregation of bones. If British speakers are more inclined to resolve such ambiguities 
in favor of an aggregate or distributive sense and American speakers are more inclined to resolve them in favor of the set sense, the observed differences in agreement would result. The hypothesis can be summarized as predicting that American speakers see a forest where British speakers see trees.

In terms of proposed psycholinguistic mechanisms of agreement, this hypothesis entails no fundamental conflicts between the dialects. For instance, on the markingand-morphing account, British speakers would be more likely than Americans to mark as plural those subject noun phrases or pronoun phrases that have collective referents, as a consequence of the bias toward distributive resolutions of ambiguous number situations. But the ensuing workings of agreement would not otherwise differ. On this view, the expected variations in overt agreement, apart from the familiar difference in collective verb agreement, involve pronoun number: since pronouns are more sensitive than verbs to variations in the notional number of their antecedents, this hypothesis predicts that pronoun number in British English, relative to American English, should track and magnify any verb number effects. That is, under conditions when verbs tend to be plural, pronouns should more strongly tend to be plural, and especially so in British English, due to the effects of concord working over and above the effects of agreement.

HYPOTHESIS 2: DIFFERENT SOURCES OF NUMBER CONSTRAINTS. The second hypothesis comes closer than the first to the spirit of the traditional account. The presupposition of most claims that British speakers use variations in number meaning in the implementation of collective agreement is that American speakers do not. Presumably, what American speakers call on are the lexical specifications, the grammatical number, of collective heads.

The mereology feature proposed for British English by Sauerland and Elbourne (2002), and the absence of the feature from American English, is one instantiation of this hypothesis. On constraint-based views of agreement, the hypothesis can be stated in terms of contrasting sources of number constraints. In setting the index that is consulted by agreeing elements, British speakers should rely on the message features or notional valuations of the number context to a greater extent than American speakers, who rely instead on features of the linguistic context. Presumably, in the course of language acquisition, British children would come to acquire sensitivity to and ability to use notional variations in the implementation of collective (and other kinds of) agreement. They might observe that a winning team comprises four rowers when they hear that Vivaldi crew set new ocean rowing record, but that the achievement reflects the team as a unit when told Vivaldi team sets a new Atlantic record. American children, in comparison, hearing that Colorado sees its four-game streak come to an end (and never Colorado see), would come to acquire sensitivity to and ability to use linguistic properties of collective (and other kinds of) head nouns: Colorado, even when it refers to a nine-man baseball team, is grammatically singular in number. In general, the upshot would be agreement systems that differ substantially in how they combine notional and lexical information during the implementation of agreement, with British speakers giving greater weight to notional than to lexical number.

In collective contexts, this hypothesis predicts several contrasting patterns between agreement and attraction and between verb and pronoun agreement in British and American English. One prediction is that the same kinds of variations that characterize agreement with collective subjects should characterize attraction to collective attractors, albeit more weakly (see Thornton \& MacDonald 2003 for a specific example of this 
constraint-satisfaction prediction). This hypothesis was explicitly tested for American speakers in Bock et al. 2004 and disconfirmed. A second prediction is that when the notional aggregation behind a collective subject is enhanced by the nonlinguistic context, British speakers should be much more likely than American speakers to use plural verb agreement. So, if British agreement is driven by deep, logical, meaning-based evaluations of numerosity in the cognitive context whereas American agreement is driven by superficial grammatical number properties, the enhancement of notional aggregation should have greater effects on the agreement of verbs with collective heads for British than for American speakers.

HyPOTHESIS 3: DIFFERENT LEXICAL SPECIFICATIONS. The third hypothesis returns to the possibility that British and American agreement work in the same ways but call on different values of an agreement feature. The agreement feature in question reflects not notional number (as in the first hypothesis), but lexically specified number. In particular, speakers of British and American English may associate different grammatical number values with collective nouns. By lexically governed convention, some speakers of British English treat nouns such as team and government as plural, in the same way that some speakers of American English treat the noun faculty as plural. More accurately, some speakers of British English treat the categories of sports-team-denoting nouns and names, and corporation-denoting nouns and names, as plurals by default, whereas American English speakers treat them as singulars by default. So, in the same way that new members of the trousers category (e.g. capris) are plural by default, some categories of collectives may be plural (and their new members treated as plural), regardless of variations in the circumstances in which they are used. The variability is not notionally controlled but lexically controlled.

The novel prediction from this hypothesis involves the impact of collective attractors. Bock et al. 2001 and Bock et al. 2004 have shown that the notional properties of collective nouns in American English have little to no ability to create attraction, either for verbs or for pronouns. Attraction appears to emanate from grammatically specified plurals only, and in marking-and-morphing terms, this is attributed to the resolution of phrasal number properties with lexical number properties that occurs during the implementation of agreement control. If the restriction of attraction to grammatically specified plurals holds in British as well as American English, and certain collectives are grammatically specified as plurals, the third hypothesis predicts a degree of attraction from collectives proportional to the likelihood of plural specification. So, relative to singular count controls, collective attractors should yield attraction proportional to other plural nouns.

This prediction is challenged in the work of den Dikken (2001), who argued that collectives do not attract. In general, this seems to be true: Bock \& Eberhard 1993 and Bock et al. 2004 found no attraction to collectives. But the research was done in American English, and with collectives that most American English speakers, most of the time, treat as singular. If collective attraction does occur, its effects are likely to be subtle: the strength of attraction is modulated by the relative frequency of contrasting forms (Bock et al. 2004), such that invariable plurals and plurals with very lowfrequency singulars are weaker attractors than variable plurals and plurals whose contrasting singulars are high in frequency. Collectives tend to have very low-frequency plural forms or lack them entirely (cf. clergy, people, cattle, police). Idiolectal differences exacerbate the difficulty of observing collective attraction by increasing variability among and within speakers. But with suitable controls and estimates of the likelihood 
of plural specification, the marking-and-morphing contention is that attraction from collectives should occur.

1.3. Summary and PREVIEW. Linguistic and psycholinguistic accounts of agreement differ along parallel dimensions involving the nature of agreement features and the ways in which features are used in the grammar and by speakers. On one set of views, features have a conceptual or referential basis that is essential to their explanation; on another, features are formal or abstract linguistic properties. On one set of views, agreement features are tapped conjointly by all the linguistic elements that bear them, giving the features a uniform interpretation; on another, agreement features are structural bonds between controllers and targets. The marking-and-morphing approach to agreement is a psycholinguistic theory that bridges these views, proposing that agreement can originate in notional features but relies on lexical and abstract syntactic features during implementation. On this approach, the properties of verb and pronoun agreement reveal how the lexicon and syntax work together to realize two forms of agreement, concord and control, that respectively maximize the interpretative and structural components of agreement implementation.

Collective agreement in British and American English offers an explanatory challenge and a test of alternative hypotheses about how agreement works, linguistically and psycholinguistically. Three competing predictions emphasize different combinations of conceptual, structural, and lexical constraints on the implementation of agreement in the two dialects, with covariations in verb and pronoun agreement serving to diagnose the nature of agreement features. The following sections report research that was designed to test the competing hypotheses, using a combination of corpus analysis, normative assessment, and experimental testing.

\section{AgREEMENT IN BRITISH AND AMERICAN ENGLISH: NORMATIVE VARIATIONS.}

2.1. Methods and materials. The first set of studies was designed to better document and quantify the variations between British and American English in the use of plural number when an agreement target's controller or antecedent has a collective head. We gathered two types of data from British and American speakers and writers. First, to assess verb agreement using matched collective and noncollective materials under comparable conditions, we elicited spoken sentence completions from American and British college students. The collective nouns sampled were chosen from a dictionary of collectives (Sparkes 1985) to represent a range of human (team, committee), nonhuman animate (herd, flock), corporate (government, association), and ostensibly inanimate (fleet, forest) groupings. Second, for a subset of these collectives we carried out counts of singular and plural verb and pronoun agreement with collective controllers in the Wall Street Journal corpus and the British National Corpus.

SPOKEN SENTENCE COMPLETIONS. To compare the incidence of plural agreement after collective controllers with the incidence of plural agreement after semantically related plural and singular noncollectives, thirty-nine students at Michigan State University and thirty-nine students and research workers at Cambridge University provided spoken sentence completions. The completion test was assembled from ninety-six triplets of semantically related nouns (see Appendix A). Each triplet consisted of a collective (e.g. army), a semantically related noncollective singular (e.g. soldier), and the corresponding plural (e.g. soldiers). Three lists of ninety-six simple definite noun phrases were assembled from these triplets, with one noun in each noun phrase (e.g. the army). Every list contained one noun from every set and an equal number of nouns of each of the 
three types (collective, singular, and plural). Across the three lists, every noun occurred just once. The order of the nouns within lists was random, constrained so that there were no more than two successive occurrences of the same kind of noun. The same random order was used for all three lists, so that nouns from the same triplet occurred in the same ordinal position in every list. Each list began with the same four practice items, consisting of two noncollective singulars and two noncollective plurals that differed from the noun phrases used within the lists.

The phrases were presented to participants individually under computer control, each phrase appearing centered on the computer monitor. Where there were spelling discrepancies in American and British (neighbor/neighbour), the spelling presented was the appropriate one for the dialect. Participants were asked to read the phrase aloud and complete it as a simple sentence, as fast as possible with the first thing that came to mind. The speakers were instructed by example to use completions consisting of the copula BE and a predicate adjective. On each trial, when the participant began to talk, the experimenter cleared the computer screen. At the completion of the trial, the participant pressed the computer's mouse to move on to the next phrase.

An additional sample of spoken completions was gathered from thirteen British students enrolled at Michigan State University, identified as British nationals by the campus administration. Their durations of residence in the United States varied. Each of the British students received the entire set of 288 definite noun phrases arranged in one of six random orders, preceded by the same four practice trials. In other respects the procedure was the same as described above.

The participants' responses were recorded, transcribed, and scored. The scoring noted whether the verb used was singular, plural, or other. The 'other' category covered cases in which the verb could not be unambiguously scored as singular or plural or the subject noun phrase was inaccurately produced.

Corpus CounTs. The part-of-speech tagged Wall Street Journal corpus and British National Corpus were searched for occurrences of the subset of collective nouns listed in Appendix B. To better equate the subject matter of the American and British texts, the search in the British National Corpus was restricted to the domain of finance and commerce. When a collective served as the subject of a clause or as the same-sentence antecedent of a third person pronoun, and was not part of a proper name, the verb or pronoun agreement target was hand-coded as singular, plural, or unspecified (for verbs with morphologically invariant number, such as past tense verbs). The search in the Wall Street Journal corpus was exhaustive. In the British National Corpus, the number of tokens for each collective was set at a maximum of 300, sampled at random from all of the texts within the domain. For the two sources, Appendix B gives the distribution across the collective nouns of the incidence of verb and pronoun tokens with unambiguous number.

2.2. NoRming Results. For the sentence completions, Table 3 shows the overall proportions of plural verbs (out of the unambiguous singulars and plurals) produced for each type of subject noun phrase by the Americans in Michigan, the British speakers in England, and the British students tested in the United States. For the American and British students the proportions are based on a possible 416 responses per cell, and for the British exchange students on a possible 1,248 per cell. To assess the statistical significance of the observed differences between the British and American speakers, an analysis of variance was performed on the proportions of plurals for each item, treating items as the random factor. This analysis showed a significant effect of the 
head noun $(F(2,95)=167.9)$, due to the substantial differences among singulars, plurals, and collectives in the tendency to elicit plural verbs. There was also a significant effect of the norming group $(F(2,190)=65.7)$ along with a significant interaction between the norming group and the type of head $(F(2,190)=58.1)$. Both of the latter effects stem from the difference between the Americans and the two British groups in the production of plural verbs with collective heads. Together, the British were about ten times more likely than the Americans to use plurals with collectives (.20 to .02), producing completions such as The flock were thick and dense, while the groups did not differ in the use of plural verbs after noncollective singular and plural head nouns.

DIALECT AND GROUP

American

British (Cambridge, England)

British (exchange students in US)

\begin{tabular}{ccc}
\multicolumn{3}{c}{ HEAD OF SUBJECT NOUN PHRASE } \\
& NONCOLLECTIVE & NONCOLLECTIVE \\
COLLECTIVE & SINGULAR & PLURAL \\
.023 & .000 & .999 \\
.186 & .004 & .993 \\
.217 & .009 & .998
\end{tabular}

TABLE 3. Proportions of plural verbs produced after collective and noncollective singular and plural subject noun phrases by American and British English speakers in sentence-completion norming.

For the corpus counts, Table 4 gives the proportions of plurals (out of the total number of singulars and plurals) that occurred among verbs and pronouns in each dialect. For both dialects the proportion of plural pronouns was higher than the proportion of plural verbs, and this difference was considerably larger for American than British sources. Comparing across dialects, plural verb agreement with collectives was much more frequent in British than in American English (.26 to .07), whereas the corresponding difference for pronouns was small (.42 to .38). To assess the strength of the relationship between the two types of agreement and between the two dialects, Pearson product-moment correlations were performed between the verb and pronoun plural proportions within each dialect and between the British and the American plural proportions for each target type (verb or pronoun). Across the collective nouns, there was a substantial correlation between verbs and pronouns in British English $(r=.71)$, but the same correlation for American English was a negligible - .05. For pronoun number, the correlation between British and American sources was .25, and for verb number it was .32 . These moderate positive correlations between the dialects imply some similarities in which collectives tend to be treated as plural in verb and pronoun agreement. Notably, the magnitudes of the correlations are similar for pronouns and verbs.

\begin{tabular}{lcc} 
& \multicolumn{2}{c}{ TARGET TYPE } \\
DIALECT OF ENGLISH & VERB & PRONOUN \\
American & .07 & .38 \\
British & .26 & .42
\end{tabular}

TABLE 4. Proportions of plural verb and plural pronoun agreement targets for collective controllers from corpus counts in the American and British financial press.

2.3. Discussion. Both the norming and the corpus counts revealed substantial differences between British and American English in the use of plural verb agreement with collective subjects. The disparities varied in size, ranging from a tenfold difference for spoken sentences produced under controlled conditions to a fourfold difference for written sentences sampled from financial newspapers. There are obviously many reasons why these proportions might differ, but the important point for present purposes 
is that American and British speakers vary substantially in how they treat verb agreement with collectives.

The corpus counts for pronouns with collective antecedents revealed no such difference, tending instead toward plural agreement in both dialects. Hundt (1998; see also Nixon 1972) observed a similar trend for the nouns government, committee, family, and police. On the assumption that the pronouns reflect discourse agreement rather than grammatical agreement, this suggests that British and American speakers are less at odds over the notional aggregation of the normal referents of collectives. However, this assumption can be challenged. Although the pronouns sampled from the corpora for our analyses appeared in the same sentences as their antecedents, they constituted a mix of reflexive and other pronouns. In addition, their positions with respect to their antecedents varied. Finally, for one collective (team), Hundt (1998) found more plural pronominal agreement in British than in American English, though not for the other four collectives in her sample. To better compare British and American speakers' use of notional number in pronoun agreement, experiment 1 examined the distributions of plural and singular pronouns when the pronoun types and antecedent locations were known.

\section{EXPERIMENT 1.}

3.1. Introduction. The goal of the first experiment was a controlled test of the hypothesis that British speakers, when implementing pronoun agreement during production, tend to be more sensitive than American speakers to variations in number within the message underpinning an utterance. The number in the message is assumed to be the notional or discourse-relevant number of the pronoun's referent. If the referent is a group introduced by a collective noun, the notional number can be ambiguous between a collective (singular) and distributive (plural) construal (see Joosten et al. 2006 for an in-depth analysis of the variations among collective nouns in their openness to this possibility). With plural-biased construals, if British speakers are more likely to attend to notional number, they should be more likely than Americans to use plural pronouns distinctively.

To create distributively biased construals, the collective-headed noun phrases used in this experiment (and the next) included plural postmodifiers in one experimental condition. These plural postmodifiers have two consequences. The first is to enhance the distributive potential of the collective head. Joosten and colleagues (2006) describe such enhancement in terms of increased accessibility of the entity level (roughly the same as what we have called the distributive construal) of a collective. For example, the committee from the unions implies representatives of multiple constituencies, individuating the committee members in a way that the committee from the union is less likely to. Humphreys and Bock (2005) found that individuation of the members of collectives increased the tendency for American English speakers to treat the collectives as plurals by about 8 percent, relative to controls; Bock et al. 1999 found an increase of 16 percent.

The second consequence of plural postmodifiers is attraction. To distinguish the effects of attraction from those of the enhanced plurality of the collective, experiment 1 employed control conditions in which the same plural postmodifiers used after collective heads also accompanied noncollective singular heads (e.g. the representative of the unions). By comparing the incidence of plural agreement targets in this condition to the incidence in a condition in which the postmodifiers were singular (e.g. the representative of the union), the rate of attraction can be estimated. With the same 
logic and similar materials, Bock et al. 1999 showed that attraction increased the use of plural pronouns (and plural verbs) by an average of 8 percent. The expectation for experiment 1 was that the effect of distributive bias should be observable by an increase in the use of plural pronouns over and above the effects of attraction.

British and American speakers could differ in their use of notional number when implementing discourse agreement but nonetheless use grammatical number in the same way when implementing grammatical agreement. To examine this possibility, we elicited two different types of pronoun agreement. The first, tag-pronoun number agreement (e.g. The crew with the peacekeeping force caroused, didn't it/they?), was expected to yield more discourse (i.e. plural) agreement due to the distinct clause membership of the pronoun and its putative antecedent. The second, reflexive-pronoun number agreement (e.g. The crew with the peacekeeping force fooled itself/themselves) should yield more grammatical (i.e. singular) agreement because of the binding relationship between the reflexive pronoun and its controller. If British and American speakers differ in how they deal with discourse agreement but not in how they deal with grammatical agreement, we should see differences in the use of singulars and plurals for tag pronouns but not for reflexive pronouns.

So, in the first experiment we elicited pronouns under controlled circumstances that allowed a more incisive evaluation of British and American speakers in their sensitivity to notional and grammatical number. We used two elicitation conditions with different grammatical contexts. The contexts were matched in the properties of the controllers but varied in the properties of the agreement relationship between the antecedents and the pronouns, as illustrated in Table 5. In the tag-pronoun condition, we elicited spoken completions to sentence fragments with collective heads, such as The crew with the peacekeeping forces caroused ...; in the reflexive-pronoun condition, we elicited spoken completions to sentence fragments with the same heads but different, reflexivecompatible verbs, such as The crew with the peacekeeping forces fooled .... The collective-head conditions were contrasted with noncollective singular (sailor) and plural (sailors) heads followed by the same prepositional phrase postmodifiers, which provided baseline estimates for the use of singular and plural pronoun agreement (see Appendix $\mathrm{C}$ for the complete set of materials).

\begin{tabular}{|c|c|c|c|}
\hline \multirow{3}{*}{$\begin{array}{l}\text { TYPE OF } \\
\text { HEAD NOUN }\end{array}$} & \multirow[b]{2}{*}{ NUMBER OF } & \multicolumn{2}{|c|}{ PREAMBLE TO ELICIT PRONOUN AGREEMENT TARGET } \\
\hline & & & \\
\hline & ATTRACTOR & TAG PRONOUN & REFLEXIVE PRONOUN \\
\hline \multirow[t]{2}{*}{ Singular } & Singular & $\begin{array}{l}\text { The sailor with the peacekeeping } \\
\text { force caroused }\end{array}$ & $\begin{array}{l}\text { The sailor with the peacekeeping } \\
\text { force fooled }\end{array}$ \\
\hline & Plural & $\begin{array}{l}\text { The sailor with the peacekeeping } \\
\text { forces caroused }\end{array}$ & $\begin{array}{l}\text { The sailor with the peacekeeping } \\
\text { forces fooled }\end{array}$ \\
\hline \multirow[t]{2}{*}{ Plural } & Singular & $\begin{array}{l}\text { The sailors with the } \\
\text { peacekeeping force caroused }\end{array}$ & $\begin{array}{l}\text { The sailors with the } \\
\text { peacekeeping force fooled }\end{array}$ \\
\hline & Plural & $\begin{array}{l}\text { The sailors with the } \\
\text { peacekeeping forces caroused }\end{array}$ & $\begin{array}{l}\text { The sailors with the } \\
\text { peacekeeping forces fooled }\end{array}$ \\
\hline \multirow[t]{2}{*}{ Collective } & Singular & $\begin{array}{l}\text { The crew with the peacekeeping } \\
\text { force caroused }\end{array}$ & $\begin{array}{l}\text { The crew with the peacekeeping } \\
\text { force fooled }\end{array}$ \\
\hline & Plural & $\begin{array}{l}\text { The crew with the peacekeeping } \\
\text { forces caroused }\end{array}$ & $\begin{array}{l}\text { The crew with the peacekeeping } \\
\text { forces fooled }\end{array}$ \\
\hline
\end{tabular}

TABLE 5. Preambles for one experimental item, experiment 1.

\subsection{METHOD.}

PARTICIPANTS. There were 384 participants in total, half British and half American. The British participants were 192 students at Cambridge University or college prepara- 
tory students in their final year of study. All were under thirty years of age and native speakers of British English (i.e. British English was the only language spoken in their childhood homes). They were without recent or extensive firsthand experience with North American English. They were paid a small sum for their service. The Americans were 192 students at the University of Illinois who took part either to partially satisfy an introductory psychology course requirement or for a small payment. They were native speakers of American English and without recent or extensive firsthand experience with British English.

EQuiPMENT. The British participants were run on either a Macintosh Powerbook 540 or 1400 with a 15" external monitor (Sony Trinitron model CBF 15 SF). Voice recordings were made over an AKG 1000 CS stand microphone connected to either an HHB PortaDAT 1000 digital tape recorder or a Marantz analog tape recorder via a Symetrix pre-amplifier. The American participants were run on a Macintosh Quadra 650 with a 17' Apple Multiple Scan monitor. Voice recordings were made over a Shure headworn microphone (SM10A) amplified by an Applied Research and Technology Professional Tube Mic Preamplifier connected to a digital-audio (Sony DTC-ZE700) or audio cassette (Realistic SCT-84) recorder. The experiment-running software was PsyScope version 1.1 (Cohen et al. 1993) and identical PsyScope scripts were used in England and the United States to ensure equivalent timing of experimental events.

Materials. The thirty-six experimental items were designed to elicit number-specified tag and reflexive pronouns from speakers. Each item consisted of a set of preambles (sentence initiations) containing a complex subject noun phrase and a regular past tense verb. Appendix $\mathrm{C}$ gives a schematic description of all of the items, and one item is illustrated in full in Table 5. As Table 5 shows, there were twelve versions of each item, involving six basic variations for eliciting each of the pronoun targets. The only difference between the preambles for the alternative pronoun targets was that the verb was intransitive in the tag-eliciting preambles, and transitive-reflexive in the reflexiveeliciting preambles. The six variants on these two preamble conditions were created from three types of head nouns (noncollective singular, noncollective plural, or collective) combined with two types of local attractors (noncollective singular or noncollective plural). For economy, we refer to the noncollective singulars and noncollective plurals simply as singulars and plurals.

An additional forty-eight preambles served as filler items. These were more diverse in structure than the experimental items, and included simple as well as complex noun phrases. Thirty of the fillers contained plural head nouns, so that in each list there was a total of forty-two plural-headed subject noun phrases. Every participant received the same set of these, modified according to pronoun condition to conclude with an intransitive or reflexive verb.

Twelve lists of eighty-four preambles were constructed from these materials. Every list began with six filler preambles, followed by a random arrangement of experimental and filler preambles constrained so that there were no consecutive experimental trials. The same random arrangement of filler and experimental items was used in all lists.

Six of the lists contained only tag-eliciting preambles and the remaining six contained reflexive-eliciting preambles. Every list contained one version of each of the thirty-six experimental items, and six preambles from each combination of type of head noun (singular, plural, or collective) and type of attractor (singular or plural). Across lists, every version of every item occurred exactly once. 
Procedure. Table 6 gives a schematic description of the experimental procedure. The preambles were displayed one at a time in 18-point Palatino font on a computer monitor. Participants were instructed to read each preamble, produce it aloud, and complete it using a pronoun. Half of the participants in each dialect group received instructions for completing the preambles with reflexive pronouns, and half received instructions for completing the preambles with tag pronouns. Participants in the respective groups were given examples of reflexive pronouns (specifically, herself, himself, itself, themselves, and ourselves) or of tag questions, which were described as 'the little questions that people sometimes put at the end of sentences, like She's crazy, isn't she? or He's not there, is he?'. The instructions also included examples of the completions expected, without any information about the number or other agreement properties of the preambles or the pronouns themselves. Practice trials followed, to ensure that participants said the preamble aloud and correctly. They were encouraged not 'to think too long about what to say' and 'to talk as fast as you can'.

EVENT

1. Visual presentation of preamble

2. Speaker repeats preamble and completes with

3. Scoring: Is the number of the agreement target singular or plural?

\section{ELICITATION CONDITIONS WITH SAMPLE RESPONSES}

TAG PRONOUN

(exp. 1)

'The actor in the soap operas rehearsed'

tag question

'The actor in the soap operas rehearsed, didn't he?'

Singular

'The actor in the soap operas rehearsed, didn't he?'

Plural

'The actor in the soap operas rehearsed, didn't they?'
REFLEXIVE PRONOUN (exp. 1)

'The actor in the soap operas watched'

'The actor in the soap operas watched himself.'

Singular

'The actor in the soap operas watched himself.'

Plural

'The actor in the soap operas watched themselves. reflexive pronoun
VERB

(exp. 2)

'The actor in the soap operas'

full sentence

'The actor in the soap operas was popular.' Singular

'The actor in the soap operas was popular.' Plural

'The actor in the soap operas were popular.'

TABLE 6. Procedures in experiments 1 and 2 for eliciting tag pronouns, reflexive pronouns, and verbs, with sample responses and scores.

Two different presentation procedures were employed, balanced across the dialect and pronoun groups. The procedures differed in the amount of time provided for reading the preambles, with one allowing the preamble to be read aloud from the screen and the second requiring the preamble to be reproduced from memory. With read-aloud presentation, each preamble was revealed by a mouse click, and when the participant began to utter the final word of the preamble, the experimenter blanked the screen. With reproduction presentation, a centered fixation point (a plus sign) initiated the trial. A mouse click revealed the preamble, which remained in view for an amount of time that allowed it to be read through once, silently, by most participants. The duration was determined by a formula that adjusted for the length of the preamble. Total presentation time was a constant $250 \mathrm{~ms}$ per character, plus an additional $25 \mathrm{~ms}$ for each function-word character and an additional $40 \mathrm{~ms}$ for each content-word character. The preamble was followed by a display containing an exclamation point as the signal to begin speaking.

With both procedures, participants completed the preambles with either a reflexive or tag pronoun. Equal numbers of British and American speakers received each of the twelve experimental lists under each of the two presentation procedures, so that the 
same numbers of participants were exposed to each combination of materials in all conditions.

SCORING. The responses on the experimental trials were transcribed from the audio tapes and scored for the number of the pronoun in the sentence completion. There were two types of valid responses, classified as Plurals and Singulars. Pronouns were scored as Plural or Singular only when the preamble was correctly reproduced, spoken just once, and the completion contained an unambiguously plural or singular pronoun of the targeted kind (i.e. a tag pronoun in the Tag condition and a reflexive pronoun in the Reflexive condition). Examples of Plural responses from the condition with plural attractors are presented in Table 7, accompanied by an example Singular response for the same item in the same condition.

All other responses were assigned to one of several defective-response categories. These categories included incorrect preamble repetitions (generally, changes in the number of the head noun or attractor), completions that omitted pronouns, and rare completions in which the pronouns were anomalous (e.g. reflexive forms such as himselves).

DATA ANALYSES. To compare the incidence of plural agreement over dialects, pronoun types, and head-noun types, analyses of variance were performed on the proportions of valid Plural responses for each participant and each item in each cell of the experimental design. The proportions were calculated relative to all valid Plural and Singular responses in each condition for each type of preamble. Prior to analysis the proportions were arcsin transformed (Smith 1976). Analyses were performed with both participants and items as random factors using the min $\mathrm{F}^{\prime}$ statistic (Clark 1973). Unless otherwise indicated, effects reported as significant were associated with probabilities less than or equal to 0.05, and the corresponding test statistics are summarized in Appendix D.

Type of preamble presentation (read-aloud or reproduction) was treated as a separate factor in the analyses. Because the major findings were similar regardless of presentation mode, we omit differences associated with presentation from the results and discussion.

3.3. Results. Figure 1 presents a summary of the results in terms of the proportions of plural tag and reflexive pronouns produced. Tables 8 and 9 give the raw numbers of Singular and Plural responses in each subject noun-phrase condition for tags and reflexives respectively. The main entries are totals over the two tasks (read-aloud and reproduction); in parentheses are the results from reproduction only.

The statistical analyses confirmed that both the type of head noun and the plurality of the attractor affected the proportion of plural responses. Significantly different proportions of plural pronouns occurred with different types of head nouns, with .09 plural after singular heads, .60 after collective heads, and .98 after plural heads. Significantly more plurals accompanied plural than singular attractors, .60 to .51 .

More notable was the absence of variation in the magnitude of these differences associated with dialect and with type of pronoun. None of the effects of head or attractor type changed significantly depending on the pronouns produced or on the dialects of the speakers. American and British speakers produced similar proportions of plural tags (.53 and .56 , respectively) and plural reflexives (.54 and .57 , respectively) and succumbed to attraction at similar rates (with increases in plural agreement after plural attractors of .12 and .08 , respectively). The overall proportion of plural pronouns used with collective subject noun phrases was slightly higher for the American than for the British speakers (.63 to .57), but not significantly so. In short, the similarities across 


\section{NUMBER OF PRODUCED TARGET (VERB OR PRONOUN) \\ SINGULAR \\ EXPERIMENT 1 \\ PLURAL (ATTRACTION)}

AMERICAN SPEAKERS

-The gang leader with the dangerous rivals armed himself.

-The singer for the church services dressed herself.

-The herd near the waterfalls grazed, didn't it?

-The relative of the Scottish monarchs disappeared, didn't he?

-The university with the warnings reformed itself.

-The professor with the research awards persevered, didn't he?

-The tourist with the expensive cameras posed, didn't she?

-The gang leader with the dangerous rivals armed themselves.

-The singer for the church services dressed themselves.

-The herd near the waterfalls grazed, didn't they?

-The relative of the Scottish monarchs disappeared, didn't they?

\section{BRITISH SPEAKERS}

-The university with the warnings reformed themselves.

-The professor with the research awards persevered, didn't they?

-The tourist with the expensive cameras posed, didn't they?

\section{EXPERIMENT 2}

AMERICAN SPEAKERS

-The gang leader with the dangerous rivals was shot.

-The driver with the warnings was cautious.

-The jury for the trials was full.

-The jazz player at the nightclubs was paid very badly.

-The protester behind the fences was angry about something.

-The fleet with the distinctive flags was recognized everywhere.

-The good reputation of the boys was challenged.

-The rumor about Mary's friends was true.

-The rhythm of the drummers was fast.

-The dress uniform of the soldiers was hideous.

-The speech prepared for the politicians was dull.

-The trophy for the best players was won by Emmanuel.

-The problem with the people was they were too loud.

-The problem with the people is that they are rude.

-The problem with the people is that they don't communicate.

\section{BRITISH SPEAKERS}

-The gang leader with the dangerous rivals were killed.

-The driver with the warnings were careful.

-The jury for the trials were biased.

-The jazz player at the nightclubs were very spontaneous.

-The protester behind the fences were very angry.

-The fleet with the distinctive flags were always seen from a distance.

\section{EXPERIMENT 3}

AMERICAN SPEAKERS

-The good reputation of the boys were at stake.

-The rumor about Mary's friends aren't true.

-The rhythm of the drummers were annoying. BRITISH SPEAKERS

-The dress uniform of the soldiers were gray.

-The speech prepared for the politicians were prepared earlier.

-The trophy for the best players were awarded at the end of the season.

\section{EXPERIMENT 4}

AMERICAN SPEAKERS

-The problem with the people are that they use all our resources.

-The problem with the people are they're dumb.

-The problem with the people were they did not speak fast enough.

TABLE 7. Sample responses from all experiments to preambles with singular heads and plural attractors. 


\section{Tag Pronoun Agreement}

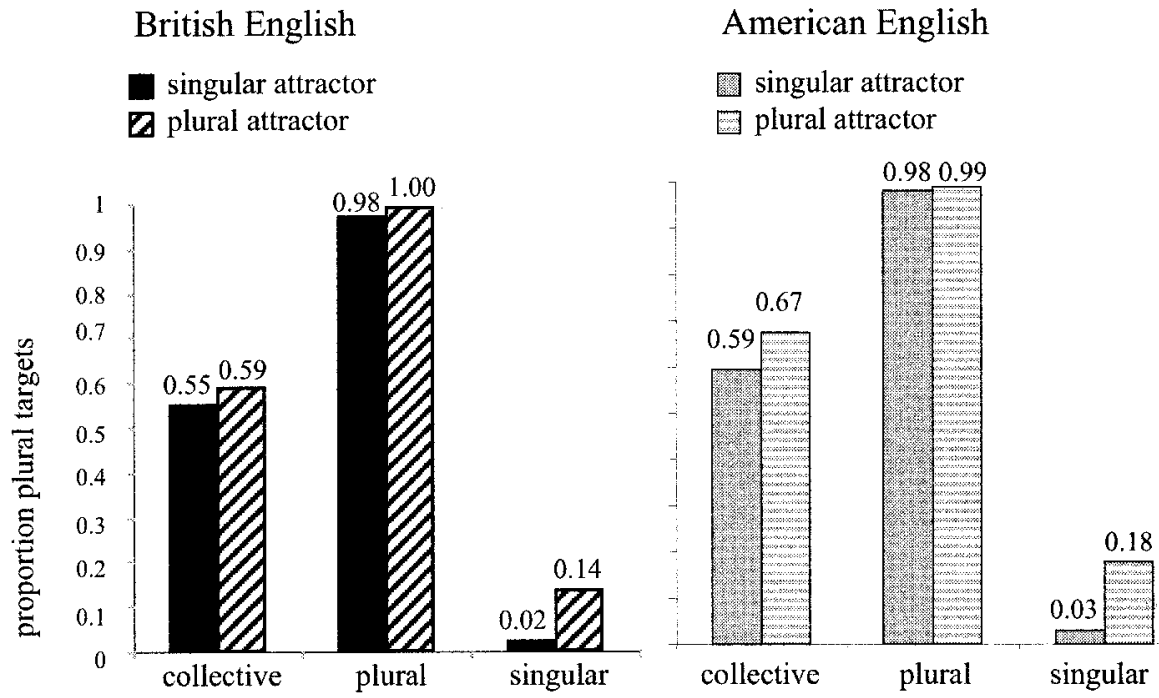

\section{Reflexive Pronoun Agreement}

singular local noun

$\square$ plural local noun

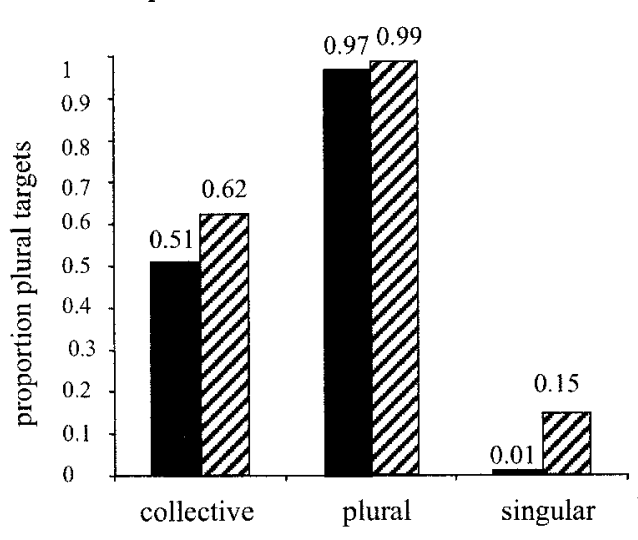

singular local noun

plural local noun

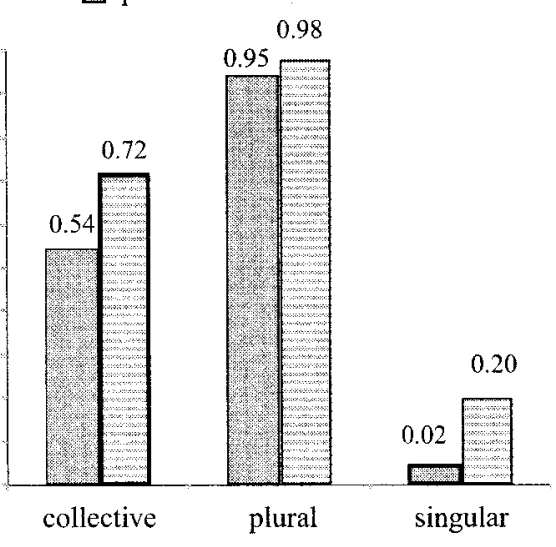

head of subject noun phrase

FIGURE 1. Proportions of plural tag pronouns and plural reflexive pronouns produced in British (left) and American (right) English in experiment 1.

speakers in pronoun use were more striking than any differences, as were the similarities in number for the reflexive and tag pronouns.

3.4. Discussion. Pronoun elicitation yielded strong evidence that both American and British speakers regard collectives as notionally plural. Relative to singular head nouns, singular collectives were substantially more likely to elicit plural pronouns. They were also substantially LESs likely than plural heads to elicit plural pronouns. This suggests that as antecedents they fall between individual singulars and plurals in 


\begin{tabular}{|c|c|c|c|c|}
\hline \multirow{3}{*}{$\begin{array}{l}\text { DIALECT AND } \\
\text { HEAD-NOUN TYPE }\end{array}$} & & \multicolumn{3}{|c|}{ PRONOUN RESPONSE CATEGORY } \\
\hline & \multicolumn{4}{|l|}{ ATTRACTOR } \\
\hline & NUMBER & SINGULAR & PLURAL & MISCELLANEOUS \\
\hline \multicolumn{5}{|c|}{ British English $(n=192)$} \\
\hline \multirow[t]{2}{*}{ Collective } & Singular & $222(129)$ & $275(130)$ & $79(29)$ \\
\hline & Plural & $187(114)$ & $270(143)$ & $119(31)$ \\
\hline \multirow[t]{2}{*}{ Plural } & Singular & 12 (10) & $477(250)$ & $87(28)$ \\
\hline & Plural & $1 \quad(1)$ & 422 (249) & $153(38)$ \\
\hline \multirow[t]{2}{*}{ Singular } & Singular & $486(258)$ & $12 \quad(8)$ & $78(22)$ \\
\hline & Plural & 370 (209) & $60 \quad(46)$ & $146(33)$ \\
\hline \multicolumn{5}{|c|}{ American English $(\mathrm{n}=192)$} \\
\hline \multirow[t]{2}{*}{ Collective } & Singular & $170(109)$ & $247(134)$ & $159(45)$ \\
\hline & Plural & $128 \quad(82)$ & $265(166)$ & $183(40)$ \\
\hline \multirow[t]{2}{*}{ Plural } & Singular & $8 \quad(6)$ & $408(242)$ & $160(40)$ \\
\hline & Plural & $4 \quad(3)$ & 373 (239) & $199(46)$ \\
\hline \multirow[t]{2}{*}{ Singular } & Singular & 419 (228) & $13(10)$ & $144(50)$ \\
\hline & Plural & $297(182)$ & $64 \quad(52)$ & $215(54)$ \\
\hline
\end{tabular}

Note: numbers in parentheses are responses in read-aloud procedure only

TABLE 8. Numbers of tag pronoun responses by category across head and attractor types in experiment 1 .

notional number, or that speakers vary more in their tendencies to treat collectives as plurals. Most important was the finding that whatever the source of this variation for collectives, it yields the same results for the two dialects. British speakers are neither more nor less likely than American speakers to use plural pronouns after collective antecedents.

Reflexive and tag pronouns were very much alike. This runs counter to the natural expectation that reflexive pronouns should reflect discourse agreement less than tag pronouns: they occur in the same clause with their antecedents, are closer to their antecedents, and are structurally bound to their antecedents (Chomsky 1981). Nonetheless, reflexives as well as tags tended to be plural when their antecedents were collectives, and to the same degree. The equivalence of reflexives and tags in their number agreement properties replicates a finding from Bock et al. 1999 for American speakers.

\begin{tabular}{|c|c|c|c|c|}
\hline \multirow{3}{*}{$\begin{array}{l}\text { DIALECT AND } \\
\text { HEAD-NOUN TYPE }\end{array}$} & & \multicolumn{3}{|c|}{ PRONOUN RESPONSE CATEGORY } \\
\hline & \multicolumn{4}{|l|}{ ATTRACTOR } \\
\hline & NUMBER & SINGULAR & PLURAL & MISCELLANEOUS \\
\hline \multicolumn{5}{|c|}{ British English $(\mathrm{n}=192)$} \\
\hline \multirow[t]{2}{*}{ Collective } & Singular & $223(141)$ & $234(116)$ & $119(31)$ \\
\hline & Plural & $145 \quad(91)$ & $240(141)$ & $191 \quad(56)$ \\
\hline \multirow[t]{2}{*}{ Plural } & Singular & 13 (10) & 443 (239) & $120 \quad(39)$ \\
\hline & Plural & $5 \quad(3)$ & 399 (239) & 172 (46) \\
\hline \multirow[t]{2}{*}{ Singular } & Singular & $473(249)$ & $5 \quad(3)$ & $98 \quad(36)$ \\
\hline & Plural & 347 (193) & $60 \quad(56)$ & 169 (39) \\
\hline \multicolumn{5}{|c|}{ American English $(\mathrm{n}=192)$} \\
\hline \multirow[t]{2}{*}{ Collective } & Singular & $157(102)$ & $188(85)$ & $231(101)$ \\
\hline & Plural & $92(62)$ & $232(147)$ & 252 (79) \\
\hline \multirow[t]{2}{*}{ Plural } & Singular & $21 \quad(20)$ & $363(212)$ & $192 \quad(56)$ \\
\hline & Plural & $7 \quad(7)$ & $340(236)$ & $229 \quad(45)$ \\
\hline \multirow[t]{2}{*}{ Singular } & Singular & $405(229)$ & $10 \quad(9)$ & $161 \quad(50)$ \\
\hline & Plural & $244(147)$ & $61 \quad(53)$ & 271 \\
\hline
\end{tabular}

Note: numbers in parentheses are responses in read-aloud procedure only

TABLE 9. Numbers of reflexive pronoun responses by category across head and attractor types in experiment 1 . 
Apparently, the number features of pronouns are determined in a way that is not sensitive to the structural locations of their antecedents, and separately from binding constraints (Joseph 1979).

There was also a trend toward increased use of plural pronouns after plural attractors. This is normal attraction (Bock et al. 1999, 2001, 2004). For both pronoun types the magnitude of attraction was the same for British as for American speakers, suggesting that speakers of both dialects are vulnerable to the spurious use of agreement features. Further, the absence of differences between reflexives and tags reinforces the evidence that number features are determined in the same ways for both kinds of pronouns. Since the sources of number information involved in canonical agreement and attraction differ (Bock et al. 2001, 2004), the similarities between tags and reflexives suggest that these sources of number come together independently of the mechanisms that determine the agreement target.

The reader may object that in tasks of the present kind speakers do not consider the sense behind what they are producing, with the implication that speakers are not observing meaning differences that they would otherwise be sensitive to. In order to address this objection, we carried out parallel notional number norming tasks in England and the United States. In these tasks, 120 judges (sixty British and sixty American) received the preambles from the experiments and were asked to indicate whether they thought the referents of the phrases represented 'one thing' or 'more than one thing'. The preambles were divided into lists so that judges saw only one version of each item, and ten judges rated every version.

The results are shown in Table 10, in terms of a measure in which 1 is the 'one thing' rating and 2 is the 'more than one thing' rating. There were consistent, significant differences in the notional ratings that paralleled the pronoun results, but again, no differences between the British and American speakers. In an analysis of variance with items as the random factor, only the type of head (collective, singular, plural) produced a significant effect, $F(2,140)=2817.0$. The effect of dialect was negligible, $F(1,70)$ $=0.10, p>0.75$. These results converge on the same interpretation as the pronounelicitation findings: speakers of British and American English are virtually identical in their sensitivity to variations in notional number.

\begin{tabular}{llll} 
& & \multicolumn{2}{c}{ ATTRACTOR NUMBER } \\
$\begin{array}{l}\text { DIALECT } \\
\text { British English }\end{array}$ & HEAD TYPE & SINGULAR & PLURAL \\
& & & \\
& Collective & $1.10(0.18)$ & $1.10(0.19)$ \\
& Plural & $1.90(0.08)$ & $1.95(0.06)$ \\
& Singular & $1.00(0.04)$ & $1.03(0.06)$ \\
American English & & & $1.18(0.10)$ \\
& Collective & $1.10(0.13)$ & $1.96(0.06)$ \\
& Plural & $1.90(0.08)$ & $1.04(0.06)$
\end{tabular}

Note: means range between 1 and 2. Numbers greater than 1 reflect increases in the frequency of notional aggregate judgments.

TABLE 10. Means (and standard deviations) for judgments by British and American English speakers of the notional number of subject noun phrases used in experiments 1 and 2 .

4. Experiment 2: verb agreEment with COlLeCtive subjects. Experiment 2 was designed to test an alternative version of the hypothesis that British speakers are more attentive or sensitive to notional number variations than American speakers. The corpus 
analysis, the first experiment, and the notional number judgments all suggest that differential attention or sensitivity is not responsible for the divergent patterns of agreement with collective nouns in British and American English. The alternative hypothesis, hypothesis 2 in $\S 1.2$, is that in subject-verb agreement, the source of the controlling information for agreement is different in the two dialects. Specifically, it may be that when verb number is at issue, British speakers are more likely than American speakers to tap into notional information, while Americans are likely to call only on the grammatical number specifications of head nouns.

This hypothesis assumes that British and American speakers engage different psycholinguistic processes when carrying out agreement, or engage processes that use different kinds of agreement-relevant information. For example, a British speaker contemplating a situation involving a series of Olympic events attended by large audiences of people might refer to the crowd at the Olympic events and tacitly evaluate whether the individuals in the crowd or the group is more relevant. If the former, the speaker may be more likely to choose the plural-agreement option offered for collectives in British English, saying the crowd at the Olympic events were. In contrast, an American speaker may be more likely to disregard any latent variations in individuation and draw only on the singular lexical specification for collectives that appears to hold in the American dialect. This would yield agreement patterns more along the lines of the crowd at the Olympic events was.

To test this, experiment 2 used a method very much like the one in the first experiment. The chief difference was that speakers received only the subject noun phrases as preambles, with instructions to complete them to make full sentences. This meant that they created their own verbs. For verbs that carried number overtly (i.e. were not regular past tense verbs), we assessed the number of the verb and its relationship to the grammatical and notional number variations in the preamble.

Other than the absence from the preambles of the verbs, the experimental and filler preambles were identical to those used in experiment 1 . An important implication is that the materials included a control for attraction, in order to rule out spurious notional effects. If British speakers are indeed more likely to call on notional number variations when implementing verb agreement, we expected to observe increased use of plural verb agreement after collectives, relative to controls, in cases where distributive construals are most likely. As in experiment 1, distributive construals were encouraged with subjects containing collective head and plural attractors (the crowd at the Olympic events). Relative to subjects with singular heads and plural attractors (the spectator at the Olympic events), where attraction should be the primary force promoting plural agreement, increases in plural agreement stemming from distributivity should be larger for British than for American speakers to the extent that British speakers use notional information in a way that the Americans do not. Although the results from experiment 1 and from the notional judgments suggest that British speakers are not generally more attentive to notional number variations, there may nonetheless be variations in the tacit use of notional number that are specific to verb agreement.

\subsection{METHOD.}

PARTICIPANTS. The participants were 192 individuals from the same sources as experiment 1, meeting the same selection criteria. Half were British and half were American. None had participated in experiment 1.

MATERIALs. The materials were the same preambles used in experiment 1 , without the verbs. So, each item included only the six versions of the complex subject noun 
phrases shown in Table 5 and listed in Appendix C. Likewise, the filler preambles were the same, but stripped of their verbs. The construction of the lists was parallel to that of the lists used in experiment 1 .

PRocedure. The only procedural change from experiment 1 was that the participants were instructed simply to repeat and complete the preambles as sentences. Half of the participants in each dialect group on each list received read-aloud presentation and the other half received reproduction presentation.

SCORING AND DATA ANALYSES. The responses on the experimental trials were transcribed and the grammatical number of the verbs produced in the sentence completions was scored. Verbs were classified as Plural or Singular only when the preamble was correctly reproduced, spoken just once, and the verb was unambiguously plural or singular. All other responses were assigned to one of two defective-response categories. The number-ambiguous category consisted of responses with verbs unspecified for number (most of these were regular past tense verbs, such as walked). Miscellaneous responses included incorrect preamble repetitions (generally, changes in the number of the head or attractor), completions that omitted a verb, and any other responses that fell outside of the categories described.

Application of these criteria resulted in 657 Singular and 598 Plural responses (19.0\% and $17.3 \%$ of all responses, respectively), 1,640 ambiguous responses (47.5\%), and 561 miscellaneous responses $(16.2 \% ; 519$ of these were incorrect preamble reproductions). The data were analyzed in the same way as in experiment 1 . Because the differences between read-aloud and reproduction presentation again had no impact on the theoretically important comparisons, we report inferential statistics only from a combined analysis of variance.

4.3. Results. Table 11 displays the number of responses of each kind produced in each condition, and Figure 2 highlights the key contrasts between British and American speakers in the production of singular and plural verbs. Considered by type of head noun, the results for British and American were the same for plural and singular head nouns. In both dialects, plural heads elicited plural verb agreement regardless of the number of the attractor. Singulars elicited predominantly singular agreement, but there was increased plural agreement when the attractor was plural, reflecting a typical attraction effect. When the head noun was collective, the results for the British and American speakers were noticeably different. With collectives, American speakers exhibited a large disparity in the use of plural verbs after singular and plural attractors. These results are consistent with the presence of attraction combined with distributive enhancement. By contrast, British speakers exhibited neither attraction nor distributive enhancement after collectives.

Analyses of variance confirmed these effects statistically. There were significant effects of dialect, of the type of head noun, of the number of the attractor, and of the twoway interactions between the factors. All of these effects stemmed from the significant interaction among dialect, head-noun type, and attractor type $\left(\min F^{\prime}(2,252)=6.22\right)$. This interaction reflects the differences in agreement and attraction between British and American speakers: with plural heads, the number of the attractor made no difference for either Americans or Britons; with singular head nouns, the number of the attractor created differences in attraction for both Americans and Britons; and with collective heads, the number of the attractor mattered only for the Americans. 


\section{Verb Agreement}

British English

singular local noun

$\square$ plural local noun
American English

singular local noun

plural local noun

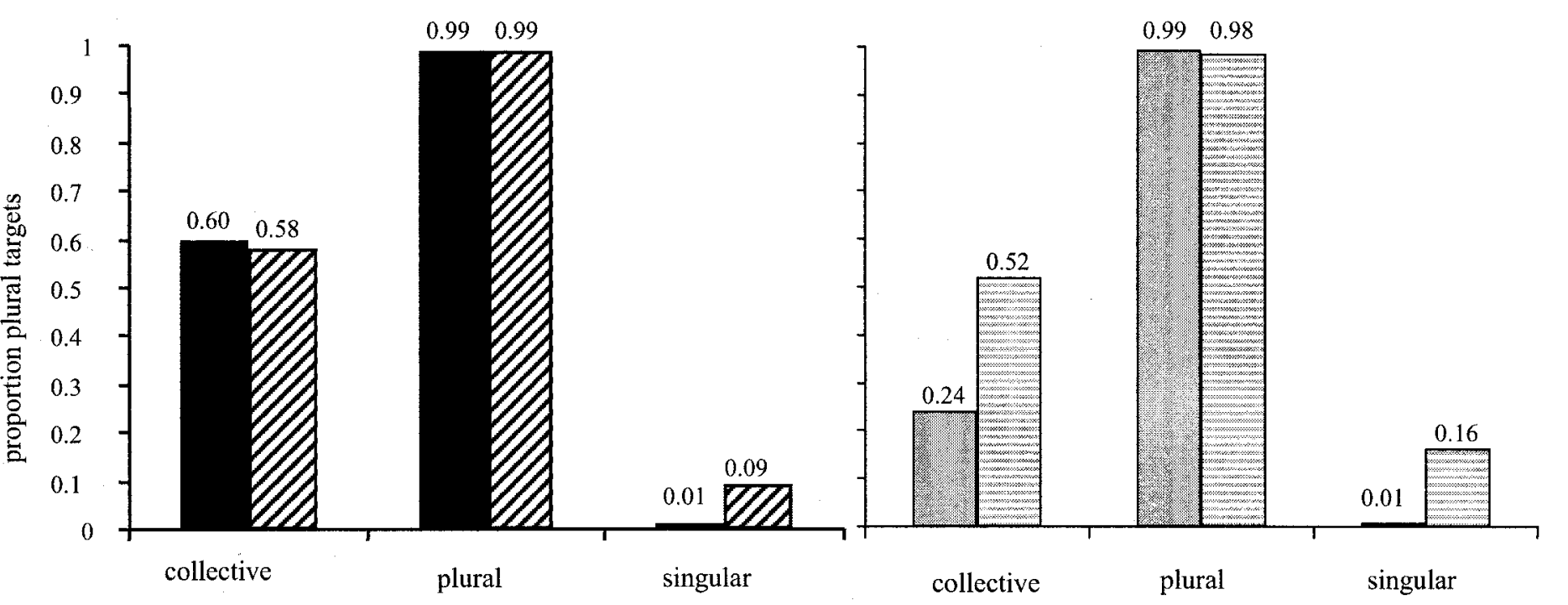

head of subject noun phrase 


\begin{tabular}{|c|c|c|c|c|c|}
\hline \multirow{3}{*}{$\begin{array}{l}\text { DIALECT AND } \\
\text { HEAD-NOUN TYPE }\end{array}$} & \multirow[b]{2}{*}{ ATTRACTOR } & \multicolumn{4}{|c|}{ VERB RESPONSE CATEGORY } \\
\hline & & \multicolumn{4}{|c|}{ NUMBER } \\
\hline & NUMBER & SINGULAR & PLURAL & AMBIGUOUS & MISCELLANEOUS \\
\hline \multicolumn{6}{|c|}{ British English $(\mathrm{n}=96)$} \\
\hline \multirow[t]{2}{*}{ Collective } & Singular & $84 \quad(47)$ & $126 \quad(65)$ & $296(157)$ & $70(19)$ \\
\hline & Plural & $91 \quad(50)$ & $125 \quad(56)$ & $292(161)$ & $68(21)$ \\
\hline \multirow[t]{2}{*}{ Plural } & Singular & $2 \quad(1)$ & $190 \quad(90)$ & $300(169)$ & $84(28)$ \\
\hline & Plural & $2 \quad(2)$ & 196 & $269(155)$ & $109(33)$ \\
\hline \multirow[t]{2}{*}{ Singular } & Singular & $223(113)$ & $2 \quad(2)$ & $307(155)$ & 44 (18) \\
\hline & Plural & 172 (93) & (9) & $301(159)$ & $86(27)$ \\
\hline \multicolumn{6}{|c|}{ American English $(\mathrm{n}=96)$} \\
\hline \multirow[t]{2}{*}{ Collective } & Singular & $157 \quad(83)$ & $50 \quad(25)$ & $297(151)$ & 72 (29) \\
\hline & Plural & $103 \quad(53)$ & $112 \quad(56)$ & $275(145)$ & $86(34)$ \\
\hline \multirow[t]{2}{*}{ Plural } & Singular & $2 \quad(2)$ & $208(112)$ & $264(141)$ & $102(33)$ \\
\hline & Plural & $3 \quad(3)$ & $192(108)$ & $244(128)$ & $137(49)$ \\
\hline \multirow[t]{2}{*}{ Singular } & Singular & $219(105)$ & $2 \quad(2)$ & $301(163)$ & $54(18)$ \\
\hline & Plural & $173 \quad(82)$ & $34 \quad(22)$ & $259(142)$ & $110(42)$ \\
\hline
\end{tabular}

4.4. Discussion. Rather than revealing a hypothesized tendency among British speakers to use notional number in the implementation of verb agreement, the results gave the appearance that if anyone did, it was the Americans who used notional number. Given a subject noun phrase such as the audience at the tennis matches, British speakers were no more likely to produce plural verbs than after the audience at the tennis match. In both cases, the proportion of plural verb agreement was relatively high, roughly the same as the average proportion of plural pronouns that British as well as American speakers produced when the same phrases served as pronominal antecedents. Surprisingly, British speakers exhibited attraction across the board when they used pronouns and, if the head nouns were singular, when they used verbs, but there was no attraction for verbs when the heads were collectives. That is, British speakers were more likely to say the audience at the tennis matches behaved themselves than the audience at the tennis matches behaved itself, with the plural local noun apparently encouraging the plural pronoun. They were no more likely, however, to use plural than singular verbs under the same conditions, producing completions along the lines of the audience at the tennis matches were well-behaved less often than the audience at the tennis matches was well-behaved.

In contrast, American speakers exhibited attraction in all of these conditions. Furthermore, with collectives, the magnitude of the difference in singular and plural verb usage after singular and plural attractors suggests that something more than simple attraction was at work. With singular head nouns, across all the verb and pronoun conditions, Americans averaged an increase in the use of plural number targets of approximately .16 after plural attractors, relative to singular attractors. With collective heads, the corresponding increase was a significantly larger .28. One interpretation of the increase is that the presence of the plural attractor magnified the tendency to construe the referent of the collective as an aggregation rather than as a set, which raised the incidence of notionally driven plural agreement. This interpretation is supported by other results (Bock et al. 1999, Humphreys \& Bock 2005). If it is right, the implication is that verb number agreement in the speech of Americans may be more likely to reflect variations in notional number than in the speech of Britons. For present purposes, this means that variations in how notional number is used are unlikely to explain the normal differences between the dialects in verb agreement with collective heads. 
The key to a different explanation may be found in the absence of verb number attraction after collectives for the British speakers. This is a standard result when head nouns are grammatically plural. Because the use of plural verbs accompanying grammatically plural heads is all but categorical, it is usually impossible to tell whether attraction is absent or merely undetectable. One interpretation of the collective results for the British speakers is that it is genuinely absent. The reasoning goes like this: assume that some collectives are lexically specified as plurals among British speakers. When a lexically specified plural collective is the head noun, its plural number reliably controls verb agreement. Under these circumstances, attraction is unlikely because the specification of the head supersedes other specifications. In the third and fourth experiments we tested this lexical specification account.

5. EXPERIMENT 3: COLLECTIVE ATTRACTORS. If the psycholinguistic mechanisms of subject-verb number agreement are identical in British and American English, and if the construals of notional number for collectives are the same, the remaining hypothesis (hypothesis 3 ) has to do with differences in lexical specification. British speakers may be more likely than Americans to specify collective words as plurals in the mental lexicon.

More precisely, there may be more grammatically plural collectives in British than in American English. So, very few collectives are reliably specified as plurals in standard American (people, cattle, and police may be the complete set); most other collectives are singular and unspecified for number. In British English, a larger minority of collectives may be conventionally plural, and therefore grammatically plural in the mental lexicons of speakers. A British speaker may use a plural verb after the word staff regardless of whether the speaker views the staff as an aggregation, simply because the word staff is plural (see Joseph 1979:n. 3 for a similar suggestion). Because there is considerable variation over speakers as well as across collective and corporate nouns in the use of plural verb agreement in collective-noun contexts, a further consideration is that differences in experience with different collectives create individual differences in lexical specifications. Unlike morphologically alternating singulars and plurals, collectives carry no overt flag to number, suggesting that variable number specifications have to be learned on a case-by-case basis, or categorized by analogy to other collectives.

To test the hypothesis that the number specifications of collectives differ between the dialects, in experiment 3 we examined attraction to collective, individual singular, and individual plural attractors. Recall that only grammatical number, the lexical specification of number, appears to attract verb or pronoun number. Previous work has shown that for American speakers, attraction does not occur with the same collectives that reliably elicit plural verb and pronoun agreement (Bock et al. 2004). Invariant plurals that differ in rated notional number (compare the notionally singular scissors and the notionally plural suds; Bock et al. 2001) both yield significant amounts of attraction that do not differ in magnitude. In short, there is little evidence for attraction to notional number.

If collectives are more likely to be specified as grammatically plural in British than in American English, we should observe plural attraction to collectives among British speakers. Den Dikken (2001) has argued that such attraction does not occur, but observation suggests otherwise: a British speaker, a botanist presenting results from research on rape (the oil seed), pointed to a slide and said This field of oil seed rape are flowering. One may quibble about whether rape in this sense is truly a collective, but for a botanist 
it is likely to be (compare The rhododendron are blooming; The clematis have wilted). To test the hypothesis more objectively, we employed a different tactic than in the previous experiments, necessitated by the low incidence of attraction among British speakers in general and the variable tendencies of collectives to be used as plurals in British English. We followed three steps.

First, from the corpora, we determined whether each of the collectives employed was plural-dominant. Specifically, we examined how often each collective was accompanied by a plural verb when the collective served as the head of a subject noun phrase. When more than 90 percent of the corpus appearances of a given collective as the head of a subject noun phrase occurred with an unambiguously plural verb (out of all unambiguous singular and plural verb forms), we treated the collective as pluraldominant and likely to carry a plural specification.

Second, in experiment 3 , we measured the incidence of unambiguously singular and plural verbs after plural attractors, to obtain an estimate of the rate of plural attraction in each dialect under the specific circumstances of the experiment. The attraction rate was defined as the increase in the proportion of plural verbs relative to the proportion of plural verbs used after singular attractors. Because any use of plural verbs after singular heads with singular attractors is unmotivated, given the materials employed, this proportion served as a control for chance.

Finally, given these empirically determined values, we calculated a predicted rate of plural attraction for each dialect and compared it to the obtained rate after collective attractors. The predicted probability was the product of the proportion of pluraldominant collectives in the sample multiplied by the observed probability of attraction after normal plurals. If collectives carry a plural lexical specification, the probability of collective plural attraction should be equal to the probability of normal plural attraction.

By design, none of the collectives employed as attractors met the criterion for plural specification in American English, so the predicted probability of plural attraction among American speakers was 0. For British speakers, ten of the thirty-six collectives in experiment 3 met the 90 percent criterion, so the predicted probability of attraction to collectives depended on determining how vulnerable the British speakers in the experiment were to attraction from normal plural nouns. We did that as follows.

\subsection{METHOD.}

PARTICIPANTS. The British participants were sixty Cambridge University students from the same population as in previous experiments. An additional thirty participants were members of the MRC Applied Psychology Unit's volunteer participant panel, drawn from the Cambridge community. The Americans were sixty undergraduates at Michigan State University who received extra credit in introductory psychology courses in return for their service. British speakers were overrepresented in the sample to compensate for their very low rates of attraction, ensuring a more reliable estimate.

EQUiPMENT. British participants viewed the materials on a Zenith laptop computer running TSCOP (Norris 1984) under DOS. Recordings were made with an AKG 1000 CS microphone and Symetrix pre-amplifier onto a Marantz analog tape recorder. In the United States, materials were presented on the screen of a Macintosh 512K and recorded onto audio cassette tapes over a lapel microphone.

Materials. Preambles for the elicitation of verb agreement were developed on the model illustrated in Table 12. There were three versions of each of thirty-six experimental items. All versions of each item had the same head noun but different attractors. In 
the singular condition the attractor was a singular, and in the plural condition the attractor was the corresponding plural. In the collective condition the attractor was a collective that was semantically related to the singular and plural, to promote the sensibility of the phrases. The collectives were chosen to have high plural-agreement values in British English, as shown in the norming tasks described earlier, and none of them elicited any plural agreement in American English. The rates of plural agreement in British English are shown in Appendix E.

\begin{tabular}{ll} 
TYPE OF ATTRACTOR & \multicolumn{1}{c}{ EXAMPLE PREAMBLE } \\
Collective & The job of the night staff \\
Plural & The job of the night workers \\
Singular & The job of the night worker
\end{tabular}

TABle 12. Preambles for one experimental item in experiment 3.

The preambles were distributed over three lists so that every list contained only one version of every experimental item. An additional fifty-six items served as fillers and were repeated on every list. The fillers consisted of simple noun phrases, all with definite determiners and a single noun or adjective-noun combination. Ten were singular and the remainder plural so that across each list, half of all items had normal plural morphology. The same random order of preambles was used in every list, with the order constrained so that eight fillers began the list, at least one filler separated all experimental items from their neighbors, and preambles representing the same experimental conditions never occurred as neighbors.

Procedure. Presentation was by the read-aloud method used in the previous experiments. Participants were seated in front of the computer and instructed to read the preambles aloud and complete them as sentences as quickly as possible with the first thing that came to mind. They were also asked to speak as fast as possible. A single example was provided, using the noun phrase the doctor and a sample completion was examining the patient.

The preambles were displayed in 14-point Courier font. On each trial the experimenter pressed a response button to reveal the preamble, and the preamble appeared 500 ms later. When the participant produced the last word of the preamble, the screen was cleared.

\begin{tabular}{|c|c|c|c|c|}
\hline \multirow[b]{2}{*}{ DIALECT AND } & \multicolumn{4}{|c|}{ VERB RESPONSE CATEGORY } \\
\hline & & & NUMBER & \\
\hline ATTRACTOR TYPE & SINGULAR & PLURAL & AMBIGUOUS & MISCELLANEOUS \\
\hline \multicolumn{5}{|c|}{ British English $(\mathrm{n}=90)$} \\
\hline Collective & 874 & 5 & 153 & 48 \\
\hline Plural & 873 & 17 & 151 & 39 \\
\hline Singular & 872 & 1 & 144 & 63 \\
\hline \multicolumn{5}{|c|}{ American English $(\mathrm{n}=60)$} \\
\hline Collective & 567 & 7 & 91 & 55 \\
\hline Plural & 517 & 56 & 102 & 45 \\
\hline Singular & 556 & 6 & 103 & 55 \\
\hline
\end{tabular}

SCORING AND DATA ANALYSES. Scoring of the verbs was carried out as in the previous experiments. There were 4,215 Singulars (79.0\% of all responses), 92 Plurals (1.7\%), 744 ambiguous (13.8\%), and 305 miscellaneous (5.6\%). The distribution of scores in all conditions is shown in Table 13. 
5.2. Result. Figure 3 displays the rates of plural attraction for British and American speakers. The attraction rate corresponds to the increase in the proportion of plural verbs after collective or plural attractors relative to the proportion of plural verbs used after singular attractors. Given (i) an overall attraction rate for British speakers of .018 after plural attractors and (ii) a corpus-based estimate of .28 of the collectives having plural specification, the predicted rate of collective plural attraction in British English is .005 . Figure 3 shows that that was precisely the value obtained.

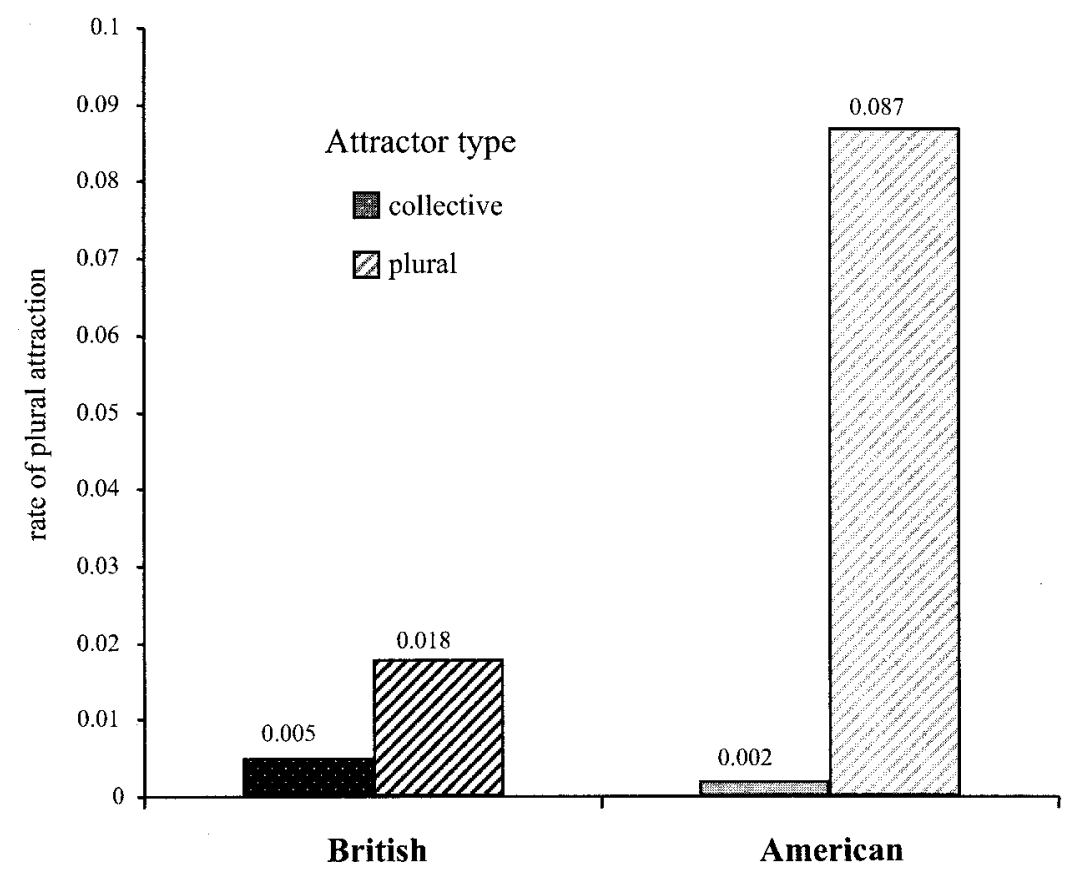

FIgURE 3. Attraction after collectives and inflected plural nouns in British and American English.

The rate of attraction for American speakers was .002. This exceeded the predicted value of 0 , which was based on the absence from the experiment of any collectives that met the corpus criterion for plural specification in American English. However, as Table 13 reveals, .002 corresponds to exactly one more plural verb after collective than after singular attractors.

5.3. Discussion. The attraction rate after plurals was almost five times larger for American than for British speakers, yet the rate after collectives was two-and-one-half times larger for the British than for the Americans. Though the absolute numbers are small, this reversal in the distribution of attraction supports the lexical-specification hypothesis for collectives: British speakers treat certain collectives as plurals with respect to verb agreement because, lexically, the collectives carry a plural number specification.

Comparative rates of attraction. The rates of attraction in British English were lower than those in American English across all of the experiments. We examined two different explanations of this disparity. One hypothesis was that there are variations in the prescriptive training that lead to the avoidance of attraction. To compare how often British and American speakers identified attracted uses of verbs as acceptable, we 
administered a forced-choice grammaticality test to ninety-six speakers of American English and thirty speakers of British English. The speakers were drawn from the same populations as those tested in experiment 3 . The test consisted of eight pairs of sentences in which the members of each pair differed only in the number of the verb; one pair is given in 9 .

(9) a. Carelessness in the use of tools causes many household accidents.

b. Carelessness in the use of tools cause many household accidents.

Half of the sentences had singular and half had plural subjects. Of the singulars, one had a simple noun-phrase subject and the other three had singular heads with plural attractors. Of the plurals, two had simple plural noun phrase subjects and two had plural heads with singular attractors.

The pairs were printed in a list on a single page, and participants were asked to check or tick the correct member of each pair. To control for order effects, the order of the singular- and plural-verb versions and the order of the expected correct and incorrect versions were counterbalanced across the pairs, and two different lists were used that varied only in the ordering of the pair members. The same materials and same lists were used for both dialects.

In both groups we examined the tendency to choose as correct the sentence from each pair whose verb mismatched the number of the head of the subject noun phrase. For British speakers the percentage of such choices was 9.2\%; for American speakers it was $8.5 \%$. The wide majority of these choices reflected plural attraction, $95.5 \%$ for British speakers and $93.8 \%$ for Americans. Clearly, the ability to recognize prescriptively correct agreement does not differ between the groups.

We also examined the possibility that British speakers responded more deliberately than American speakers, thereby reducing the likelihood of error. All of the singular and plural responses to all of the experimental items for the 120 university students in experiment 3 (where the attraction rates were lowest for British speakers) were digitized and the durations of the responses were measured, along with the accompanying latencies from the pausing of the tape recorder (which was audible on the audio tapes) to the onset of speech on each trial. We focused on the latencies to speech, the durations of the subject noun phrases (the preambles), and the length of any pauses between the ends of the preambles and the onsets of the number-inflected verbs. These measurements revealed that British speakers actually responded more rapidly and spoke faster than American speakers, reaching the verb on average after 1.96 seconds compared to the Americans' 2.11 seconds (a difference that was significant by items, $F_{2}(1,35)=17.7$, but not participants, $\left.F_{1}(2,118)=1.98\right)$. Overall, however, the British and American speakers showed similar patterns of responding on all measures. In terms of the summary measure that includes time to reach the verb, both groups were fastest with singular attractors (1.91 and 2.07 seconds for the British and Americans, respectively), slower with collectives (1.95 and 2.12 seconds), and slowest with plurals (2.00 and $2.15 \mathrm{sec}-$ onds). None of these differences were significant, and none of the other measures revealed divergent patterns.

One remaining conjecture is that British speakers may be more likely to monitor their speech for attraction. If so, they may slow down selectively, lowering their speech rates primarily in the presence of potential agreement problems. To explore this, we correlated the time-to-verb measures for each item with the proportions of attraction for the same items in the condition with plural attractors. The correlations were performed separately for the British and American college students. For the British speakers, the 
correlation was modest but significant, $r(36)=0.33, p<0.05$, hinting at a tendency to speak more slowly on those items most likely to elicit attraction. For the American speakers, there was no discernable relationship between speech rate and attraction, $r(36)=-0.02$. This suggests that the source of the difference in vulnerability to attraction may be found in differential monitoring of speech.

6. EXPERIMENT 4: people, cattle, AND police IN AMERICAN ENGLISH. Because we intentionally omitted from experiment 3 any collectives that American speakers reliably treat as plurals, we cannot yet claim with complete confidence that British and American speakers engage in the same basic linguistic operations when implementing agreement. If they do, Americans should also be susceptible to attraction from plural collectives. In experiment 4 we tested this hypothesis on American speakers.

For this purpose we called on the miniscule inventory of collectives that most native speakers of American English know and treat categorically as plural. There are in fact only three of them, the collectives people, cattle, and police. These were used as attractors in the experimental items, along with five types of controls designed to explore other properties potentially relevant to the occurrence of attraction. Among other things, the array of controls helped to ensure that the anticipated few cases of attraction after people, cattle, and police were not chance occurrences.

\subsection{Method.}

PARTICIPANTS. The participants were 150 undergraduates at Michigan State University, all native speakers of American English. They received course credit or a small payment in return for their service in the experiment. None of them took part in any of the previous studies.

MATERIALS. The experimental materials are listed in Table 14. There were only three items, each of which appeared in one of six versions. All versions of all items had singular head nouns followed by prepositional phrases, with the only differences among the versions occurring in the noun phrases within the prepositional phrases (i.e. in the attractors). The six types of attractors were uninflected collective plurals (e.g. people), simple singulars (e.g. individual), the corresponding plurals (e.g. individuals), collective singulars that are intuitively aggregations (e.g. society), collective singulars that are intuitively more group- or corporate-like (e.g. nation), and the plurals of the collective groups (e.g. nations).

\begin{tabular}{llcc} 
& \multicolumn{2}{c}{ PREAMBLES AND ATRACTORS } \\
Condition & $\begin{array}{c}\text { The command } \\
\text { to the } \ldots\end{array}$ & $\begin{array}{c}\text { The noise } \\
\text { of the } \ldots\end{array}$ \\
Invariant plural collective & people & police & cattle \\
Singular noncollective & individual & officer & cow \\
Inflected plural noncollective & individuals & officers & cows \\
Singular collective aggregate & society & navy & herd \\
Singular collective group & nation & army & flock \\
Inflected plural collective & nations & armies & flocks
\end{tabular}

TABLE 14. Materials for experiment 4.

Six lists were constructed such that (i) each contained one version of each of the three items, (ii) the three item versions within a list represented the same types of attractors, and (iii) across lists all versions of all items occurred once. Every list contained, in addition, forty-five filler items analogous to the fillers used in experiment 3. Of the forty-five fillers, twenty-four were plural, and twenty-one were singular. The 
same random arrangement of items was used in each list, constrained so that eighteen fillers preceded the first experimental item and a minimum of nine fillers separated the experimental items.

Procedure. The preambles were presented auditorily. The filler and experimental preambles were digitally recorded by a female speaker of American English and dubbed to analog tapes in the order predetermined for each list. During the experimental sessions, the experimenter played the preambles from a list one by one from a cassette tape recorder, pausing the tape as a signal for the participant to respond. The participants were instructed to repeat and complete each preamble as a sentence. Their responses were recorded and transcribed as before.

SCORING. The verbs produced in the responses were classified as in the previous experiments. A breakdown of the responses is shown in Table 15. The totals in each scoring category were 331 Singulars (74.0\%), 19 Plurals (4.2\%), 74 ambiguous (16.4\%), and 26 miscellaneous (5.8\%).

\begin{tabular}{lcccc} 
& \multicolumn{3}{c}{ VERB SCORING CATEGORY } \\
ATTRACTOR & SINGULAR & PLURAL & AMBIGUOUS & MISCELLANEOUS \\
Singular & 65 & 0 & 9 & 1 \\
Plural & 58 & 4 & 9 & 4 \\
Collective singular group & 58 & 0 & 8 & 9 \\
Collective singular aggregation & 52 & 0 & 18 & 5 \\
Collective plural (uninflected) & 55 & 3 & 15 & 2 \\
Collective plural (inflected) & 43 & 12 & 15 & 5
\end{tabular}

TABLE 15. Responses in experiment 4.

6.2. Results. As in experiment 3 , we calculated the predicted probability of collective plural attraction based on the observed incidence of attraction in the Plural attractor condition. The rate of attraction in that condition was .065. If covertly plural-specified collectives create attraction at the same rate, we should observe the same incidence of attraction in the uninflected Collective plural condition. The actual rate was .052 . The three errors of attraction that occurred were all after the collective people.

The only other condition in which plural attraction occurred was with inflectedplural collectives (e.g. nations). Reminiscent of other experiments in which plural collectives were used (Bock \& Eberhard 1993, Bock et al. 2004), these plurals elicited attraction at an unusually high rate (.22). None of the singulars, either collectives or simple count nouns, produced any attraction at all.

6.3. Discussion. The results suggest that categorically plural collectives can create attraction among American speakers, and, just as for British speakers, that they do so at roughly the same rates as normally inflected count plurals. This provides the evidence that attraction occurs from categorically plural collective nouns for both British and American speakers.

We found attraction only for the collective people, and not at all for cattle or police. Given the very low rates of attraction, it is impossible to rule out chance absences in accounting for this, although other factors may be in play. The most likely is frequency: in word-frequency counts, people occurs much more often than police and cattle (902 to 155 to 97 times per million words in the Brown corpus; Francis \& Kucera 1982). The frequency of invariable plurals increases their attractiveness (Eberhard et al. 2005). Along related lines, the disproportionate amount of attraction to plural collectives (e.g. 
nations) can be attributed to the RELATIVE frequency of plural to singular forms for individual count nouns. Because of these factors, invariable plurals (e.g. scissors, suds) create significantly less attraction than their normally inflected counterparts (Bock et al. 2001), and rare plurals (nouns that very infrequently inflect with overt plural morphology, collectives included) trigger correspondingly MORE attraction (Bock et al. 2004). So, frequency and contrastiveness contribute jointly to the strength of attraction.

6.4. Converging corpus analyses. Although the rates of collective attraction in experiments 3 and 4 are consistent with the hypothesis that the difference between British and American speakers is primarily one of grammatical number categorization, they were low enough to make converging evidence desirable. To strengthen the conclusion, we examined more closely the corpus distributions of plural verbs used with the collectives from our sample. Figure 4 shows the results for the collectives that occurred at least once as the subjects of verbs in the British and American corpora. The graph indicates the percentage range of plural verbs that accompanied each collective when the collective headed the verb's subject. The incidence of plural verb use is given in $10 \%$ intervals between 0 and $100 \%$. As before, percentages were calculated from the number of unambiguous plural verbs relative to the total of unambiguous singular and unambiguous plural verbs.

For British collective usage, the figure reveals a bimodal distribution. More than two-thirds of the collectives (nineteen) are either singular-dominant or plural-dominant, with the remainder in between. American usage, in contrast, is unsurprisingly singulardominant for twenty of the collectives. There is little difference between the dialects in the numbers of collectives occupying the intermediate ranges where lexically independent, notionally controlled usage might be reflected. However, the specific words that occur are not the same. Only gang and majority appear in the midranges for both dialects.

It might be argued that the distributions reflect some bias within our relatively small sample of collectives. Perhaps few of them are amenable to notional variation, either because of their semantics or their typical contexts of occurrence. To examine this, we also compared the distributions in the corpora for plural pronouns used with collective antecedents. Just as we did for the verb counts, we calculated the percentages of plural pronouns (out of all singulars and plurals) whose antecedents were unambiguously identifiable as one of the collectives in our sample. Figure 5 displays the results. Unlike the verbs, the uses of plural pronouns with collective antecedents are distributed relatively evenly across the full frequency range, for both British and American English. In terms of their pronominal anaphors, some collective antecedents are predominantly singular, some are predominantly plural, but the majority fall somewhere in between.

6.5. The problem of AtTRibutives. A remaining objection to the lexical account of the dialect difference in collective verb-number agreement is that it predicts unattested dialectal variations in determiner agreement (what Corbett 2000 called ATTRIBUTIVE AGREEMENT). Corbett (2000:189; see also Sauerland \& Elbourne 2002) asserted that 'In attributive position ... only singular is possible'. To prospect for these variations, we carried out an exploratory norming study in which sixty American and seventyfour British college students were asked to rate the acceptability of singular and plural demonstrative determiners (this or these) combined with specific collectives (including all of those used in the present experiment) and other singular and plural nouns. The ratings were done on a five-point scale ranging from 1 (completely acceptable) to 5 (completely unacceptable). For most of the collectives, the differences were negligible: 


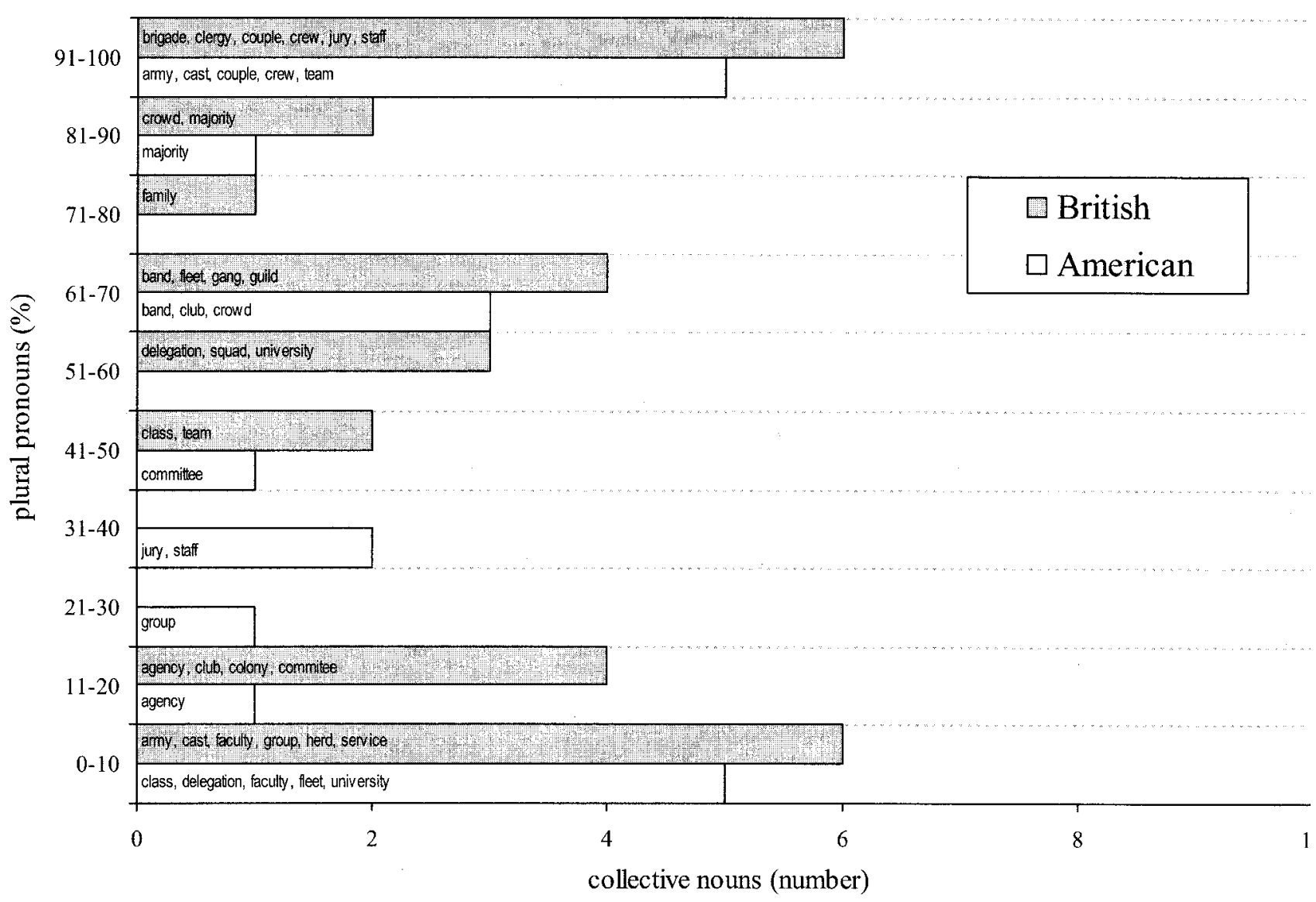

FIGURE 4. Distribution of collective nouns with respect to observed proportions of plural verb agreement in American and British English corpora. 


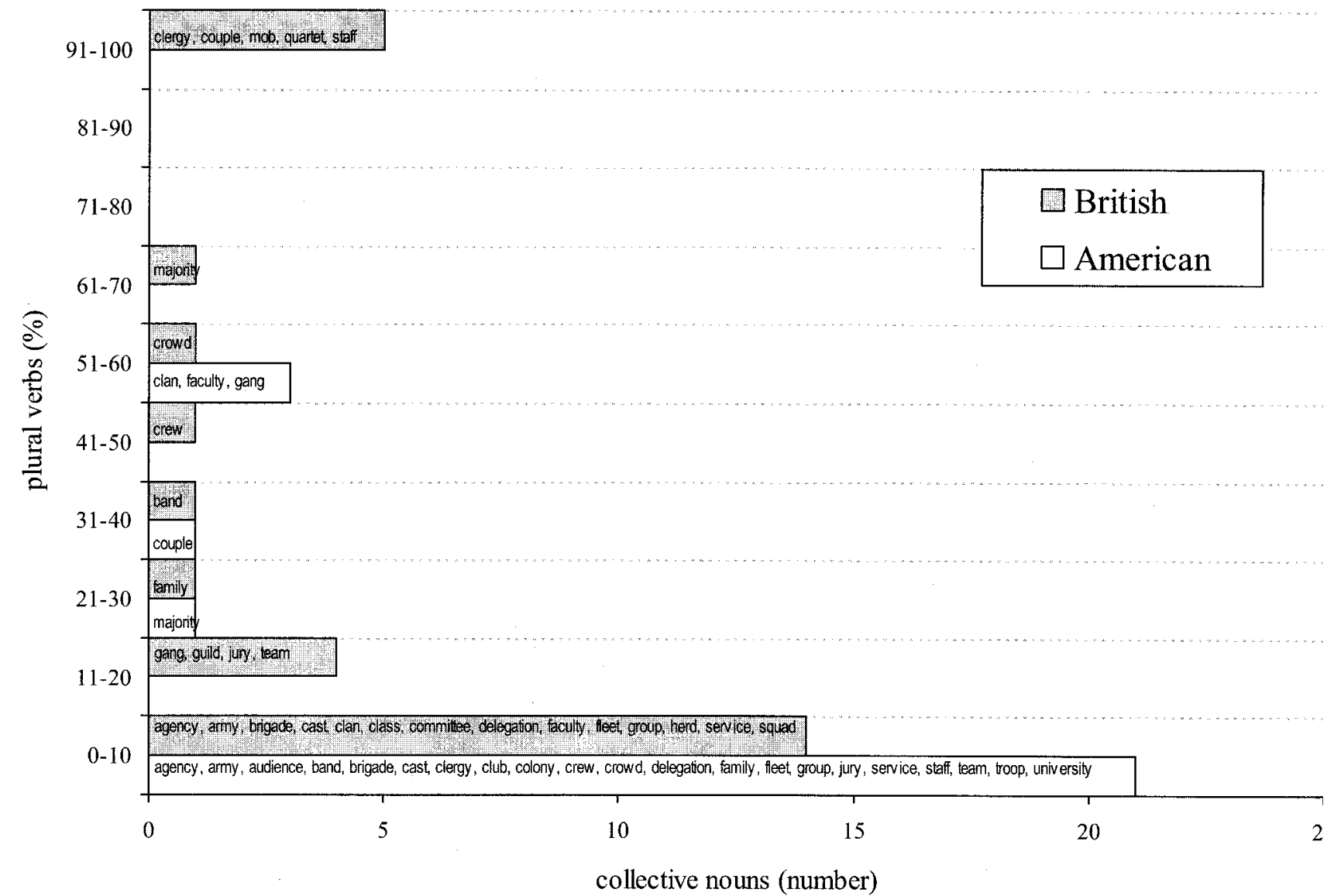

FIGURE 5. Distribution of collective nouns with respect to observed proportions of plural pronoun agreement in American and British English corpora. 
both British and American speakers found phrases such as these crowd to be highly unacceptable (mean ratings of 4.9 and 4.6, respectively), whereas these clergy was comparatively acceptable to both groups (mean ratings of 1.6 and 1.5, respectively). Overall, the American and British judgments differed by an average of just .2, a fifth of a scale point.

In a few cases, however, the judgments diverged sharply. These staff, these jury, and these crew were fairly acceptable to the British raters (with an average rating of 2.9 compared to the Americans' 4.0), and these staff was actually rated as more acceptable than this staff (1.8 vs. 2.1). In contrast, these faculty was relatively acceptable to the Americans (2.8) but decidedly not to the British (4.5). So, consistent with our other results, it appears that a few superficially singular collectives carry covert plural specifications that allow them to occur even with plural determiners, and that this is indeed more likely for British than for American speakers.

7. General discussion. Our results for British and American collective agreement suggest that lexically controlled features are responsible for the differences in plural agreement between the varieties. In spontaneous speaking, specifications of plurality for particular collectives and not dynamic variations in underlying conceptualization create the differences. This is consistent with the third of the three hypotheses we tested, the one that attributes the differences between the dialects to differences in lexically specified number among collective nouns. The lexicons of individual speakers of a dialect may differ as to which collectives are specified as plural, for reasons that may be traced to differences in linguistic experience but in any case are typical of most types of lexical variation. Across speakers, there will be variability in which collectives are treated as plurals, but lexical rather than notional variability drives the patterns of usage that we found in both experimental elicitation and corpus distribution.

Normal usage of the word data among research psychologists offers a case in point. The singular datum being virtually obsolete, the natural, untutored inclination is to treat data as a mass noun, therefore singular. Against this inclination, American graduate students in psychology, and even undergraduates in elite research-oriented programs, are heavily schooled to treat the word data as plural (see the Publication manual of the American Psychological Association, 2001, p. 89). Public utterances such as the data is and this data are unlikely to pass a faculty audience without loud correction (the data ARE; THESE data), and few written occurrences escape the red pen or the copy editor. So, graduate training imposes plural verb use on what for many is a natively singular noun, one with the conceptual features normally associated with mass nouns. When successful, the product of this training is a conceptually unsupported, lexically controlled plural specification for data.

The effects of this regimen nicely illustrate our hypothesis about the lexical source of the differences between collective agreement in British and American English. In particular, observations of data attraction and agreement among well-trained speakers of the plural-data dialect suggest that these speakers indeed have a plural lexical specification for data.

(10) a. The collection of the data were

b. I think that the interpretation of the data are controversial

c. The great thing about these data are

d. The last bit of data we collected were on

e. The first kind of data we looked at were

f. once that data are retrieved 
g. The data don't look quite as nice as I would like it to.

h. The data itself are okay, you know?

The last example, produced by one of the authors, is revealing. The verb is plural, in line with professional convention, but the logophoric reflexive is singular, in line with the stubborn, ineradicable mass construal of the normal referent of data. The penultimate example illustrates the same point. A similar clash between verb and pronoun number was shown in example 5 (repeated below) in a British Prime Minister's use of a corporate noun.

(5) It's clear that this is the reaction of an embattled Tory party that believe it's going to lose.

Although these overt clashes between verb and pronoun number are much rarer than separate instances of wayward agreement in verbs and pronouns (because the morphological number specifications of the verbs and pronouns naturally constrain each other; see Eberhard et al. 2005), they do occur. Hundt's (1998) corpus analysis found clashes in both the American and British press, with the expected tendency for pronouns to be plural when verbs were singular.

A review of the evidence in terms of the three hypotheses we tested may help to clarify these conclusions. We began with two versions of the traditional account of British collective subject-verb number agreement, whereby British speakers call on differences in perceived or conceived collective number while Americans do not. On the first version of the hypothesis, the difference is in conceptualization alone, with Americans conceiving of collectives uniformly (with few exceptions) as singulars. The results of personal pronoun usage in the two dialects argue against this account, inasmuch as British and American speakers display the same, substantial amount of variability in the use of plural pronouns with collective antecedents.

The second hypothesis, a stronger version of the traditional account, attributes notional control of number variability to British speakers and lexical control to American speakers. In its strongest form, with respect to British English, this hypothesis is reminiscent of Whorfian views about the influence of language on thought (Lucy 1992a,b). Counter to it, we observed little inclination on the part of British speakers to change verb number in accord with variations in the distributivity of subject noun phrases; indeed, judging from variations in the use of plural verbs after distributive subjects, American speakers tended to be more sensitive than British speakers to the possibility of distributive construals.

The third hypothesis was evaluated in a different experimental test, which considered whether British speakers are more likely than Americans to treat collectives as grammaticized plurals. Consistent with evidence that attraction occurs in response to the lexical number specifications of attractors rather than notional number, the results of experiment 3 showed that British speakers were more likely than American speakers to exhibit attraction to collective local nouns, to a degree precisely in line with the lexical statistics for collective plural agreement. Experiment 4 revealed a similar tendency among American speakers for those collectives that are invariably plural in American English. With respect to verb agreement, corpus data revealed a bimodal distribution of singular and plural collectives in British English but a unimodal distribution in American English. With respect to pronoun agreement, the same collectives in both dialects covered a uniform range of singular and plural agreement. Finally, normative ratings of phrases coupling singular and plural determiners (attributives) with collectives also revealed differences between the dialects consistent with the lexical account. 
From a psycholinguistic perspective, then, the results favor a view in which the basic grammatical and processing mechanisms of American and British English are the same, functioning along lines proposed in Eberhard et al. 2005. On this account, the dialectal variations fall out of a relatively minor difference in conventional lexical number specifications. There are other indications of lexical rather than conceptual convention: as noted in the introduction, the prescription of BBC Radio News is that collectives should be plural, but BBC Online says (or say, as BBC Radio would have it) they should be singular. Consistent with the traditional explanation of collective variability, the BBC Styleguide (Allen 2004) recommends thinking about whether an organization is 'seen as a singular entity or as a collection of individuals' (p. 31). The difficulty for speakers is that such thinking demands much more time than most occasions of spontaneous speech allow. Obviously, speakers (as well as writers) CAN cogitate about such matters; we are not saying that this never occurs. Our claim is simply that stored lexical specifications are more likely to control agreement for most speakers most of the time, and that variability in specification is a more likely source of dialect variability than variability in thinking or in the processes of agreement themselves.

This is inconsistent with existing accounts of the nature of the difference between American and British collective agreement. There is nothing in our data to suggest that British speakers are more alert than American speakers to the notional-number possibilities implicit in number-ambiguous circumstances or that British speakers implement agreement differently, using different number features. Apart from plural verb agreement with collective-headed subject noun phrases, the only thing setting British speakers apart was their greater resistance to attraction from plural local nouns. Consistent with this resistance was a tendency among British speakers to speak more slowly in regions with plural attractors prior to verb onset. The implication is that the avoidance of attraction is a consequence of monitoring one's speech (Hartsuiker \& Kolk 2001) and not a consequence of the basic mechanisms of agreement implementation.

Apart from this, a complete account of collective agreement in British English must include a productive subcategory of corporate nouns. It is not just existing collectives that take plural agreement. The names of agencies, corporations, teams, and the like take plural agreement, even when the agencies are completely fictional (e.g. the Ministry of Magic). In the same way that new members of the category of leg-encasing garments tend to become overtly plural in English (the pedalpushers and clamdiggers of the 1950s American wardrobe), in British English new members of the corporate category may be treated as covert plurals for the purpose of verb agreement. The only contrast with American speakers involves verb agreement (and perhaps attributive agreement for some words), since in pronoun agreement, collectives tend to be treated as plural in both dialects. It is in the classification processes that create the lexical subcategories where we see conceptual number (or a mereology feature; Sauerland \& Elbourne 2002) playing a part.

For linguistic theories of agreement, our findings point to mechanisms that operate differently for verbs than for pronouns. English verb agreement works in ways that suggest directional control in the determination of number features, in line with derivational accounts of syntax. English pronoun agreement instead reflects concord in notional or referential indices, as suggested by constraint-satisfaction theories. The similarities between verbs and pronouns in their vulnerability to attraction, and the strong evidence for directional structural involvement of lexical specifications, imply that there are mentally represented linguistic structures in which verb and pronoun agreement are treated equivalently. In these domains, a unified treatment of verb and 
pronoun agreement seems feasible for accounts that take the phenomenon of attraction as linguistically relevant (as in den Dikken 2001).

The results for pronoun agreement in experiment 1 are problematic for binding theory (Chomsky 1981). The similarities in the data for reflexive and tag pronoun number suggest that the forms and distributions of pronouns are not well correlated with the distributions of agreement features: both reflexive pronouns and tag pronouns tend to be plural after singular collective antecedents, and to the same degree. Both also tend to undergo attraction to grammatical plurals, to the same degree. At a minimum, the implication is that the agreement features of pronouns are not subject to the same constraints as the selection of their lexical or morphological forms (e.g. the use of the -self suffix; Joseph 1979).

Our account of the results, and our explanation of the difference between British and American agreement, is couched in terms of a psycholinguistic theory that incorporates mechanisms often posed as competitors rather than compatriots in other theories. Explaining the variability in English subject-verb number agreement demands semantic modulation of a strongly structural or abstract syntactic process; explaining the variability in English pronoun number agreement demands abstract structural modulation of a strongly semantic process. To account for the variability that they share, most obviously in attraction but also in agreement, requires an account of how structural and semantic processes work together. Accordingly, our processing approach to verb and pronoun agreement (Eberhard et al. 2005) includes semantically driven lexical retrieval mechanisms and notionally sensitive structural annotations, similar to elements of constraint satisfaction. These processes drive the creation of linguistic representations for sentence production and the interpretation of representations in comprehension. In addition, our approach includes mechanisms of structural manipulation that are isolable from (and capable of independent operation in the absence of) conceptual input, similar to elements of more formal or derivational approaches in linguistics.

This synchronic, psycholinguistic perspective on the nature of agreement should not be seen as supplanting or vying with historical or variationist accounts of agreement differences. Regardless of historical patterns and social influences, speakers confront anew the cognitive challenges of creating agreement every few seconds in running speech. Our question is how they actually do it, in terms of the linguistic information they call upon in real time and the dynamic mental processes that manipulate the information. These are the terms of psycholinguistic theory. How languages come to be the way they are and under what historical and social forces are complementary matters to be gainfully treated from different theoretical perspectives (see Hazen 2000, Hundt 1998, and Tagliamonte 1998 for valuable discussions).

To anticipate a few of the objections to our results and our interpretation of them, we close with a look at some of the weaknesses in what we have done and some of the most pressing questions that remain open. The dialectal differences we examined are filtered through idiolects, and the idiolects of our speakers may not well represent the norms of the dialects in question. All of the speakers were young adults. Almost all of the British speakers represent a privileged elite, attending exclusive colleges at one of the most exclusive universities in Great Britain. This clearly makes them unrepresentative, but for our purposes they provide a very good test of how well the best-educated speakers of British English realize the number distinctions that separate British from American English. To wit: if Cambridge are insensitive to the nuances of number, chances are good that most other British speakers are, too. 
We recognize the artificiality of sentence-completion tasks and the concern that the resulting data may lack validity with respect to the issues we addressed. Previous work, however, has shown that the tasks elicit responses with properties similar to utterances that occur in spontaneous speech, in particular with respect to the distribution of attraction (Bock \& Miller 1991), and many of the results we report have been replicated repeatedly. The tasks reveal reliable, linguistically principled effects of semantic (Eberhard 1999, Humphreys \& Bock 2005, Vigliocco \& Hartsuiker 2002), structural (Bock \& Cutting 1992, Franck et al. 2002, Vigliocco \& Nicol 1998), and morphological (Hartsuiker et al. 2003) variations on agreement. More generally, psycholinguistic research on speech errors has shown that laboratory tasks elicit the same kinds of variability as are evident in corpora of spontaneous speech (Cutler 1981, Cutler \& Henton 2004, Ferber 1993, Garrett 1982, Stemberger 1992). The results are nonetheless open to challenge from future observations; they serve as just one set of tests of the hypotheses we set out in the introduction. Many others are possible.

Among other desirable tests there are different tasks and different contexts of evaluation, different comparison conditions, different agreement controllers, and different agreement targets. The scope of our work (two dialects, three types of agreement targets, two task variations) demanded that we limit the number of variations in agreement controllers and contexts and the diversity of the items that we tested. More deliberate selections of collective nouns are especially desirable, and we hope our results motivate others to pursue these kinds of variations in detail.

In the psycholinguistic literature, a repeated objection to sentence-completion tasks is that they tap comprehension as well as production. For theories that aim to explain one or the other but not both, this is indeed a drawback. But because parallel results have been reported for agreement processes in tasks that emphasize comprehension over production (Nicol et al. 1997, Pearlmutter et al. 1999), we are optimistic that in time, a relatively unified processing account may explain both the comprehension and the production of agreement in much the same terms.

So, we have reported evidence for a psycholinguistic account of number agreement that makes sense of the differences between British and American English. The explanation is different from traditional views of these differences, emphasizing lexical factors over conceptual and notional ones. The bridges from this account to competing linguistic approaches suggest that there is psycholinguistic merit in both constraint-satisfaction and derivational explanations of agreement processes, and that mechanisms reminiscent of the principles of both accounts play important parts in normal language processing.

8. Summary. Combining experimental, corpus, and normative data, the results suggest that one of the most striking syntactic differences between British and American English is not necessarily attributable to greater sensitivity to number nuances on the part of British speakers, nor to undue abandon on the part of American speakers. Speakers of both dialects appear to implement number agreement in very similar ways, with only differences in the lexical-number specifications of collectives serving to distinguish them.

The results support an account of English number agreement that unifies the psycholinguistic mechanisms behind the realization of verb and pronoun number. The major source of number information for both is in the messages of speakers; both undergo number reconciliation processes within linguistic structural representations. The major difference in number agreement between verbs and pronouns, according to the present account, is that pronouns display concord in number with their antecedents whereas verbs acquire number only under structural syntactic control from their subjects. 
APPENDIX A: NOUNS USED IN SPOKEN-COMPLETION NORMS

\begin{tabular}{|c|c|c|}
\hline COLLECTIVE & NONCOLLECTIVE SINGULAR & $\begin{array}{l}\text { NONCOLLECTIVE PLURAI } \\
\text { scholars }\end{array}$ \\
\hline academy & scholar & scholars \\
\hline administration & administrator & administrators \\
\hline agency & agent & agents \\
\hline army & soldier & soldiers \\
\hline assembly & student & students \\
\hline association & associate & associates \\
\hline audience & spectator & spectators \\
\hline band & drummer & drummers \\
\hline battalion & leader & leaders \\
\hline brigade & general & generals \\
\hline brood & hen & hens \\
\hline brothel & prostitute & prostitutes \\
\hline bureaucracy & bureaucrat & bureaucrats \\
\hline cartel & dealer & dealers \\
\hline cast & actor & actors \\
\hline cavalry & rider & riders \\
\hline choir & singer & singers \\
\hline clan & relative & relatives \\
\hline class & pupil & pupils \\
\hline clergy & bishop & bishops \\
\hline clientele & client & clients \\
\hline clique & friend & friends \\
\hline club & member & members \\
\hline coalition & ally & allies \\
\hline cohort & comrade & comrades \\
\hline college & teacher & teachers \\
\hline colony & pilgrim & pilgrims \\
\hline committee & chairperson & chairpersons \\
\hline commune & companion & companions \\
\hline community & inhabitant & inhabitants \\
\hline company & employee & employees \\
\hline congregation & worshipper & worshippers \\
\hline convent & nun & nuns \\
\hline corporation & executive & executives \\
\hline council & councilor & councilors \\
\hline county & commissioner & commissioners \\
\hline crew & sailor & sailors \\
\hline crowd & protestor & protestors \\
\hline democracy & legislator & legislators \\
\hline establishment & chief & chiefs \\
\hline faction & supporter & supporters \\
\hline faculty & professor & professors \\
\hline family & parent & parents \\
\hline federation & partner & partners \\
\hline fellowship & follower & followers \\
\hline fleet & mariner & mariners \\
\hline flock & bird & birds \\
\hline fraternity & boy & boys \\
\hline gang & delinquent & delinquents \\
\hline gentry & aristocrat & aristocrats \\
\hline government & governor & governors \\
\hline group & individual & individuals \\
\hline guild & assistant & assistants \\
\hline harem & concubine & concubines \\
\hline herd & cow & cows \\
\hline institution & affiliate & affiliates \\
\hline
\end{tabular}




\begin{tabular}{|c|c|c|}
\hline $\begin{array}{l}\text { COLLECTIVE } \\
\text { jury }\end{array}$ & $\begin{array}{l}\text { NONCOLLECTIVE SINGULAR } \\
\text { judge }\end{array}$ & $\begin{array}{l}\text { NONCOLLECTIVE PLURAL } \\
\text { judges }\end{array}$ \\
\hline kin & cousin & cousins \\
\hline league & confederate & confederates \\
\hline litter & kitten & kittens \\
\hline majority & constituent & constituents \\
\hline military & commander & commanders \\
\hline militia & guard & guards \\
\hline minority & voter & voters \\
\hline mob & rioter & rioters \\
\hline monastery & monk & monks \\
\hline navy & captain & captains \\
\hline neighborhood & neighbor & neighbors \\
\hline nobility & king & kings \\
\hline orchestra & musician & musicians \\
\hline pack & $\operatorname{dog}$ & dogs \\
\hline parish & parishioner & parishioners \\
\hline parliament & politician & politicians \\
\hline party & guest & guests \\
\hline platoon & warrior & warriors \\
\hline populace & resident & residents \\
\hline posse & deputy & deputies \\
\hline prison & prisoner & prisoners \\
\hline public & citizen & citizens \\
\hline regiment & fighter & fighters \\
\hline royalty & queen & queens \\
\hline school & principal & principals \\
\hline senate & senator & senators \\
\hline settlement & settler & settlers \\
\hline society & civilian & civilians \\
\hline sorority & girl & girls \\
\hline squad & officer & officers \\
\hline staff & worker & workers \\
\hline swarm & bee & bees \\
\hline team & player & players \\
\hline town & mayor & mayors \\
\hline tribe & Indian & Indians \\
\hline troop & trooper & troopers \\
\hline union & manager & managers \\
\hline university & dean & deans \\
\hline village & peasant & peasants \\
\hline
\end{tabular}

APPENDIX B: COLLECTIVE NOUNS NORMED FROM CORPORA

Numbers of tokens of unambiguous Singular or Plural agreement targets from corpus counts VERBS PRONOUNS

$\begin{array}{lrccc}\text { COLLECTIVES } & \text { AMERICAN } & \text { BRITISH } & \text { AMERICAN } & \text { BRITISH } \\ \text { agency } & 104 & 19 & 10 & 34 \\ \text { army } & 9 & 22 & 1 & 42 \\ \text { audience } & 23 & & 0 & \\ \text { band } & 6 & 5 & 3 & 8 \\ \text { brigade } & 1 & 2 & 0 & 4 \\ \text { cast } & 5 & 1 & 2 & 4 \\ \text { choir } & 0 & 0 & 0 & 0 \\ \text { clan } & 2 & 0 & 0 & 1 \\ \text { class } & 5 & 5 & 2 & 12 \\ \text { clergy } & 1 & 1 & 5 & 3\end{array}$




COLLECTIVES
club
colony
committee
couple
crew
crowd
delegation
faculty
family
fleet
gang
group
guild
herd
jury
majority
mob
quartet
service
squad
staff
team
troop (troupe)
university

\begin{tabular}{|c|c|c|c|}
\hline \multicolumn{2}{|c|}{ VERBS } & \multicolumn{2}{|c|}{ PRONOUNS } \\
\hline AMERICAN & BRITISH & AMERICAN & BRITISH \\
\hline 6 & 16 & 0 & 37 \\
\hline 3 & 8 & 16 & 3 \\
\hline 52 & 27 & 11 & 43 \\
\hline 19 & 23 & 2 & 11 \\
\hline 2 & 9 & 2 & 11 \\
\hline 8 & 5 & 3 & 6 \\
\hline 6 & 4 & 3 & 4 \\
\hline 2 & 17 & 1 & 29 \\
\hline 33 & 11 & 0 & 17 \\
\hline 2 & 5 & 1 & 14 \\
\hline 2 & 3 & 0 & 7 \\
\hline 301 & 28 & 111 & 46 \\
\hline 0 & 3 & 0 & 6 \\
\hline 0 & 1 & 0 & 4 \\
\hline 23 & 1 & 3 & 8 \\
\hline 15 & 7 & 8 & 15 \\
\hline 0 & 0 & 0 & 1 \\
\hline 0 & 0 & 0 & 1 \\
\hline 49 & 2 & 0 & 5 \\
\hline 0 & 4 & 0 & 4 \\
\hline 29 & 14 & 8 & 37 \\
\hline 28 & 21 & 7 & 41 \\
\hline 2 & 0 & 0 & 0 \\
\hline 11 & 2 & 3 & 15 \\
\hline
\end{tabular}

APPENDIX C: MATERIALS FOR EXPERIMENTS 1 AND 2

HEAD NOUN PHRASE:

Collective/ SINGULAR(PLURAL)

The gang/gang leader(s)

The jury/judge(s)

The committee/ representative(s)

The majority/politician(s)

The herd/elephant(s)

The protest group/ protester(s)

The mob/student(s)

The army/soldier(s)

The clan/relative(s)

The choir/singer(s)

The university/driver(s)

The audience/spectator(s)

The team/player(s)

The fleet/ship(s)

The class/pupil(s)

The dance troupe/ dancer(s)

The cast/actor(s)

The crew/sailor(s)

The faculty/professor(s)

The fire brigade/

firefighter(s)
PREPOSITIONAL POSTMODIFYING

PHRASE: Singular(PLURAL)

ATTRACTOR

with the dangerous rival(s)

for the trial(s)

from the union(s)

at the meeting(s)

near the waterfall(s)

behind the fence(s)

outside the state building(s)

with the easygoing

commander(s)

of the Scottish monarch(s)

for the church service(s)

with the warning(s)

at the tennis match(es)

in the advertisement(s)

with the distinctive flag(s)

in the writing competition(s)

under the bright light(s)

in the soap opera(s)

with the peacekeeping force(s)

with the research award(s)

outside the building(s)
REFLEXIVE/TAG PRONOUN-

ELICITING VERB (EXPERIMENT 1 ONLY)

armed/vanished

disqualified/deliberated

defended/voted

represented/prevailed

cleaned/grazed

entertained/chanted

handcuffed/picketed

indulged/relaxed

introduced/disappeared

dressed/practiced

reformed/reformed

behaved/shouted

disgraced/sprinted

betrayed/surrendered

prepared/improved

presented/complained

watched/rehearsed

fooled/caroused

prided/persevered

distinguished/rested 
HEAD NOUN PHRASE:

Collective/ SINGULAR(PLURAL)

The police/officer(s)

The student club/ debutante(s)

The crowd/competitor(s)

The cleaning agency/ cleaning lady(ies)

The actors' guild/famous actress(es)

The delegation/director(s)

The clergy/priest(s)

The couple/widow(s)

The boy scout troop/ young boy scout(s)

The rock band/band leader(s)

The secret service/secret agent(s)

The jazz quartet/jazz player(s)

The family/tourist(s)

The staff/secretary(ies)

The nudist colony/ nudist(s)

The camera crew/ photographer(s)
PrepositionAL POSTMODIFYING PHRASE: SingULAR(PLURAL) ATTRACTOR

with the security company(ies) in charge of the party(ies)

at the Olympic event(s)

for the clinic(s)

in charge of the charity benefit(s)

from the wealthy foundation(s) from the rural church(es)

with the trust fund(s)

at the campground(s)

with the powerful amplifier(s)

from the foreign country(ies)

at the nightclub(s)

with the expensive camera(s)

for the training program(s)

near the sand dune(s)

from the local station(s)
REFLEXIVE/TAG PRONOUNELICITING VERB (EXPERIMENT 1 ONLY)

protected/gambled allowed/gossiped

enjoyed/waited outdid/arrived

embarrassed/celebrated

exempted/departed absolved/prayed consoled/retired warmed/misbehaved

deafened/strutted

hid/blundered

promoted/improvised

photographed/posed asserted/quit concealed/sunbathed

endangered/hurried

APPENDIX D: INFERENTIAL STATISTICS FROM EXPERIMENTS 1 AND 2

\section{SOURCE OF VARIANCE}

Dialect

Pronoun type

Head noun type

Attractor number

Dialect $\times$ pronoun type

Dialect $x$ head noun type

Dialect $\times$ attractor number

Pronoun type $\times$ head noun type

Pronoun type $x$ attractor type

Head noun type $x$ attractor number

Dialect $\times$ pronoun type $x$ head noun type

Dialect $\times$ pronoun type $\times$ attractor number

Dialect $\times$ head noun type $\times$ attractor number

\begin{tabular}{|c|c|c|c|c|c|}
\hline \multicolumn{2}{|c|}{ BY PARTICIPANTS } & \multicolumn{2}{|c|}{ BY ITEMS } & \multicolumn{2}{|c|}{ MIN $F^{\prime}$} \\
\hline DEGREES OF & $F_{1}$ & DEGREES OF & $F_{2}$ & DEGREES OF & $F$ \\
\hline FREEDOM & VALUE & FREEDOM & VALUE & FREEDOM & VALUE \\
\hline \multicolumn{6}{|c|}{ Experiment 1: Tag and reflexive pronouns } \\
\hline 1,380 & 2.1 & 1,35 & 1.0 & 1,75 & 0.7 \\
\hline 1,380 & 3.3 & 1,35 & 0.6 & 1,49 & 0.5 \\
\hline 2,760 & 230.9 & 2,70 & 746.1 & 2,686 & $157.9^{*}$ \\
\hline 1,380 & 134.7 & 1,35 & 69.7 & 1,79 & $46.0^{*}$ \\
\hline 1,380 & 0.5 & 1,35 & 0.8 & 1,191 & 0.3 \\
\hline 2,760 & 6.1 & 2,70 & 4.5 & 2,202 & 2.6 \\
\hline 1,380 & 3.6 & 1,35 & 5.3 & 1,177 & 2.2 \\
\hline 2,760 & 0.4 & 2,70 & 1.1 & 2,580 & 0.3 \\
\hline 1,380 & 3.9 & 1,35 & 11.4 & 1,300 & 2.9 \\
\hline 2,760 & 13.5 & 2,70 & 3.9 & 2,115 & 3.0 \\
\hline 2,760 & 0.2 & 2,70 & 1.1 & 2,781 & 0.2 \\
\hline 1,380 & 5.0 & 1,35 & 1.5 & 1,59 & 1.2 \\
\hline 2,760 & 2.3 & 2,70 & 0.6 & 2,111 & 0.5 \\
\hline
\end{tabular}




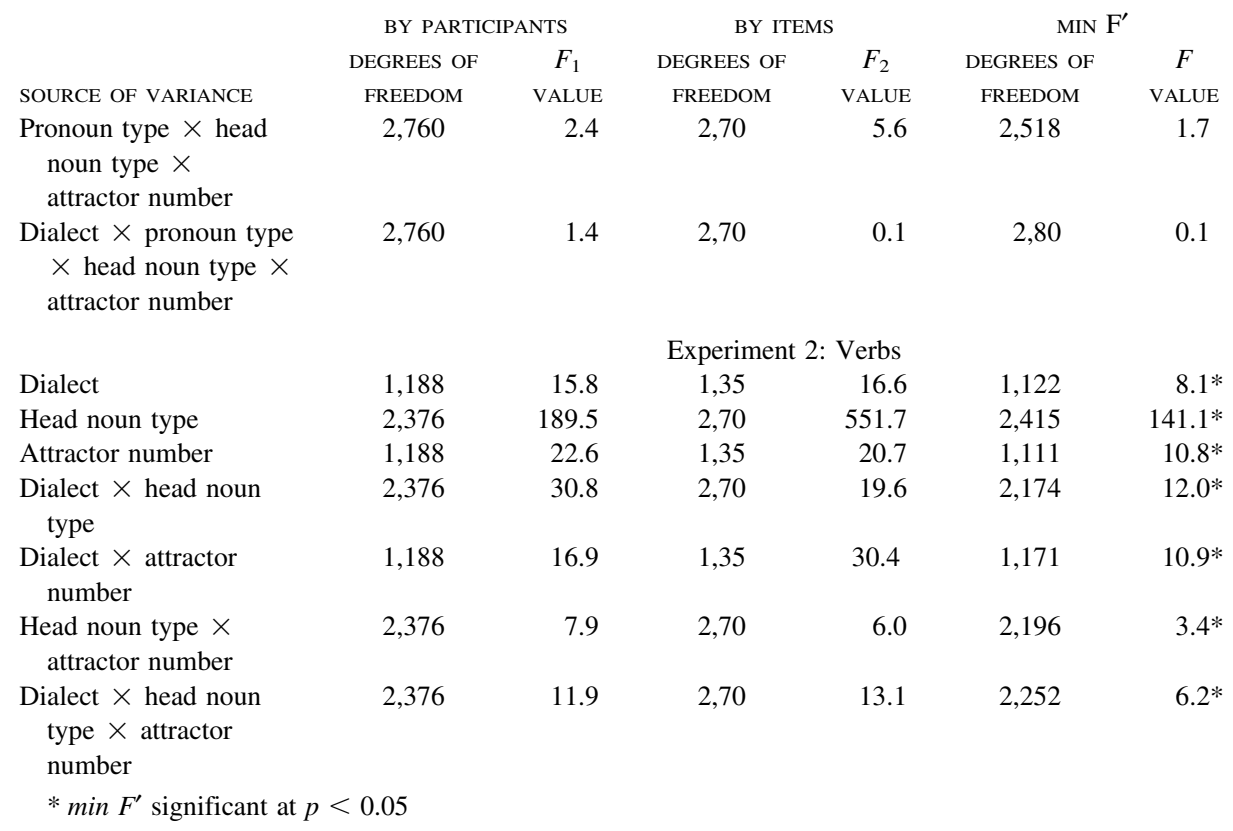

APPENDix E: MAterials FOR EXPERIMENT 3

PREAMBLE ONSET

The job of the night

The boat waiting for the

The attitude of the

The prayer offered up by the

The daily routine of the

The good reputation of the

The nest intended for the

The strategy conceived by the

The trophy for the best

The opinion of the

The dance of the Navajo

The slogan chanted by the

The announcement made to the

The clear duty of the

The owner of the

The impressive title of the

The courage of the

The rumor [rumour] about Mary's

The decision of the

The territory defended by the

The recommendation of the city

The sudden attack by the

The punishment of the rebellious

The barricade evaded by the

The brilliant performance by the

The future of the Russian

The triumph of the

The illegal profit of the
COLLECTIVE/PLURAL/SINGULAR

$$
\text { ATTRACTORS }
$$

staff/workers/worker

crew/sailors/sailor

military/commanders/commander

congregation/worshippers/worshipper

militia/guards/guard

fraternity/boys/boy

brood/hens/hen

battalion/leaders/leader

team/players/player

populace/residents/resident

tribe/Indians/Indian

mob/rioters/rioter

assembly/students/student

public/citizens/citizen

herd/cows/cow

guild/assistants/assistant

platoon/warriors/warrior

clique/friends/friend

jury/judges/judge

pack/dogs $/$ dog

council/councilors/councilor

swarm/bees/bee

squad/officers/officer

crowd/protestors/protestor

cast/actors/actor

brigade/generals/general

navy/captains/captain

cartel/dealers/dealer
BRITISH

NORM

VALUE* $^{*}$

(.796)

(.692)

(.538)

(.154)

(.231)

(.308)

(.273)

(.231)

(.308)

(.385)

(.231)

(.385)

(.231)

(.385)

(.154)

(.385)

(.308) 
PREAMBLE ONSET

The dress uniform of the

The speech prepared for the

The defeat of the

The policy of the

The concert by the young

The immediate destination of the

The rhythm of the

The gift for David's

\begin{tabular}{lc}
\multicolumn{1}{c}{ COLLECTIVE/PLURAL/SINGULAR } & BRITISH \\
$\quad$ ATTRACTORS & NORM \\
army/soldiers/soldier & $(.231)$ \\
parliament/politician/politicians & $(.231)$ \\
regiment/fighters/fighter & $(.077)$ \\
government/governors/governor & $(.250)$ \\
orchestra/musicians/musician & $(.231)$ \\
fleet/mariners/mariner & $(.231)$ \\
band/drummers/drummer & $(.154)$ \\
family/parents/parent & $(.154)$
\end{tabular}

* The British norm value is the proportion plural verb agreement for the collective noun, as measured in the Cambridge-British norming. The corresponding American value was 0 in all cases.

APPENDIX F: OBSERVED EXAMPLES OF CONTRASTING USAGE IN COLLECTIVE AGREEMENT IN AMERICAN AND BRITISH ENGLISH

(1) staff

American: $\quad$ Staff does need to report, but students do not need to report

British: $\quad$ Our staff make us who we are

(2) crew

American: $\quad$... notify the coxswain if a following crew is about to make a pass.

British: $\quad$ The St. Ives crew were pleased to medal

(3) press

American: The press is critical to Sundance

British: The press are literally over the moon

(4) audience

American: $\quad$ The news radio audience is more male than female

British: As long as the audience are quiet...

(5) government agencies, corporations, and sports teams

American: The object is what NASA describes as 'a heavily modified' 1953

Ford pickup truck

British: How are NASA going to save the earth?

American: $\quad$ By spring the Pentagon plans to let most of them come home

British: The Pentagon are being fairly cagey

American: Water District Maintains That Target of Clean Water Act is Industrial Polluters

British: The South Florida Water Management District have been taken to court

American: $\quad$ Francisco Partners [a law firm] is pleased to announce the following appointments

British: Diamond only do car insurance for women

American: $\quad$ But ABC, along with Fox, has also paid millions of dollars for interviews or specials with Mr. Jackson

British: $\quad$ BBC 1 are showing a documentary on what's in store on the fasttrack graduate medical course

American: $\quad$ Mr. Murdoch's father, Rupert, is chairman of the News

Corporation, which owns 35 percent of BSkyB.

British: 'Owned by News International, who also owns [sic] Today newspaper'. ([sic] in the original, from the Guardian, quoting the editor of a Murdoch tabloid)

American:

The Benchmade Knife company has manufactured quality knives since 1988

British: $\quad$ Corrie of Petersfield have manufactured this Easi-Kneeler Stool 


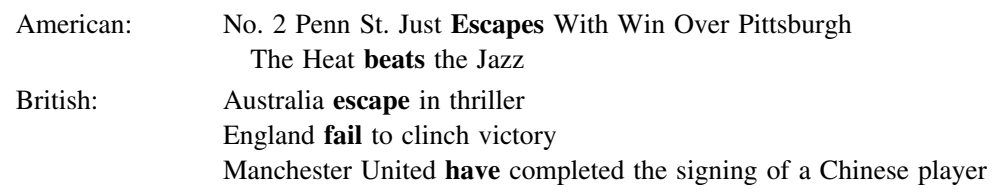

\section{REFERENCES}

Allen, John. 2004. The BBC News styleguide. Online: http://www.bbctraining.com/style guide.asp; October 31, 2004.

American Psychological Association. 2001. Publication manual of the American Psychological Association. Washington, DC: American Psychological Association.

Bock, J. KATHRYN. 1982. Towards a cognitive psychology of syntax: Information processing contributions to sentence formulation. Psychological Review 89.1-47.

BocK, J. KATHRYN. 2004. Psycholinguistically speaking: Some matters of meaning, marking, and morphing. The psychology of learning and motivation, ed. by Brian $\mathrm{H}$. Ross, 109-44. San Diego, CA: Elsevier.

Bock, J. Kathryn, and J. Cooper Cutting. 1992. Regulating mental energy: Performance units in language production. Journal of Memory and Language 31.99-127.

Bock, J. Kathryn, and Kathleen M. Eberhard. 1993. Meaning, sound, and syntax in English number agreement. Language and Cognitive Processes 8.57-99.

Bock, J. Kathryn; Kathleen M. Eberhard; and J. Cooper Cutting. 2004. Producing number agreement: How pronouns equal verbs. Journal of Memory and Language $51.251-78$.

Bock, J. Kathryn; Kathleen M. Eberhard; J. Cooper Cutting; Antje S. Meyer; and Herbert J. Schriefers. 2001. Some attractions of verb agreement. Cognitive Psychology $43.83-128$.

Bock, J. Kathryn, and Carol A. Miller. 1991. Broken agreement. Cognitive Psychology 23.45-93.

Bock, J. Kathryn; Janet Nicol; and J. Cooper Cutting. 1999. The ties that bind: Creating number agreement in speech. Journal of Memory and Language 40.330-46.

Bresnan, JoAn, and SAm A. МсномBo. 1987. Topic, pronoun, and agreement in Chichewa. Language 63.741-82.

Chomsky, NoAm. 1981. Lectures on government and binding. Dordrecht: Foris.

Chomsky, Noam. 1995. The minimalist program. Cambridge, MA: MIT Press.

Clark, Herbert H. 1973. The language-as-fixed-effect fallacy: A critique of language statistics in psychological research. Journal of Verbal Learning and Verbal Behavior $12.335-59$.

Cohen, Jonathan D.; Brian MacWhinney; Matthew Flatt; and Jefferson Provost. 1993. PsyScope: An interactive graphic system for designing and controlling experiments in the psychology laboratory using Macintosh computers. Behavior Research Methods, Instruments, \& Computers 25.257-71.

COMrIE, Bernard. 1981. Language universals and linguistic typology. Chicago: University of Chicago Press.

Corbett, Greville G. 1979. The agreement hierarchy. Journal of Linguistics 15.203-395.

Corbett, Greville G. 2000. Number. Cambridge: Cambridge University Press.

Cutler, AnNe. 1981. The reliability of speech error data. Linguistics 19.561-82.

Cutler, Anne, and Caroline G. Henton. 2004. There's many a slip 'twixt the cup and the lip. On speech and language: Studies for Sieb G. Nooteboom, ed. by Hugo Quené and Vincent van Heuven, 37-45. Utrecht: Landelijk Onderzoekschool Taalwetenschap.

Dell, GaRy S. 1986. A spreading-activation theory of retrieval in sentence production. Psychological Review 93.283-321.

DEN DikKen, MARCEl. 2001. 'Pluringulars', pronouns and quirky agreement. The Linguistic Review 18.19-41.

Drosdowski, Gunther. 1984. Duden Grammatik der deutschen Gegenwartssprache, vol. 4. Mannheim: Dudenverlag. 
DuRIE, MARK. 1986. The grammaticization of number as a verbal category. Berkeley Linguistics Society 12.355-70.

EBerhaRd, KathlEEN M. 1997. The marked effect of number on subject-verb agreement. Journal of Memory and Language 36.147-64.

EberhaRd, KATHLEEN M. 1999. The accessibility of conceptual number to the processes of subject-verb agreement in English. Journal of Memory and Language 41.560-78.

Eberhard, Kathleen M.; J. CoOper Cutting; and J. Kathryn Bock. 2005. Making syntax of sense: Number agreement in sentence production. Psychological Review 112.531-59.

Fayol, Michel; Pierre Largy; and Patrick Lemaire. 1994. Cognitive overload and orthographic errors: When cognitive overload enhances subject-verb agreement errors: A study in French written language. The Quarterly Journal of Experimental Psychology 47A(2).437-64.

FERBER, Rosa. 1993. Wie valide sind Versprechersammlungen? Zur Abschätzung von Perzeptionseffekten in Versprechersammlungen. Bern: Peter Lang.

Francis, Winthrop Nelson, and Henry Kucera. 1982. Frequency analysis of English usage: Lexicon and grammar. Boston: Houghton Mifflin.

Franck, Julie; Gabriella Vigliocco; and Janet Nicol. 2002. Subject-verb agreement errors in French and English: The role of syntactic hierarchy. Language and Cognitive Processes 17.371-404.

Fromkin, Victoria. 1971. The non-anomalous nature of anomalous utterances. Language 47.27-52.

Garrett, Merrill F. 1975. The analysis of speech production. The psychology of learning and motivation 9, ed. by Gordon H. Bower, 133-77. London: Academic Press.

Garrett, Merrill F. 1982. Production of speech: Observations from normal and pathological language use. Normality and pathology in cognitive functions, ed. by Andrew W. Ellis, 19-76. London: Academic Press.

Garrett, Merrill F. 1988. Processes in language production. Linguistics: The Cambridge survey 3: Language: Psychological and biological aspects, ed. by Frederick J. Newmeyer, 69-96. Cambridge: Cambridge University Press.

Goldstein, Norm (ed.) 2004. The Associated Press stylebook. New York: Basic Books.

Hartsuiker, Robert J., and Herman H. J. KolK. 2001. Error monitoring in speech production: A computational test of the perceptual loop theory. Cognitive Psychology 42.113-57.

Hartsuiker, Robert J.; Herbert J. Schriefers; J. Kathryn Bock; and Gerdien M. KiksTRA. 2003. Morphophonological influences on the construction of subject-verb agreement. Memory \& Cognition 31.1316-26.

Haskell, Todd R., and Maryellen C. MacDonald. 2003. Conflicting cues and competition in subject-verb agreement. Journal of Memory and Language 48.760-78.

HAZEN, KIRK. 1996. Dialect affinity and subject-verb concord: The Appalachian-Outer Banks connection. SECOL Review 20.25-53.

HAZEN, KIRK. 2000. Subject-verb concord in a post-insular dialect: The gradual persistence of dialect patterning. Journal of English Linguistics 28.127-44.

HuMPHREYS, KARIN R., and J. KATHRYN BOCK. 2005. Notional number agreement in English. Psychonomic Bulletin \& Review.

Hundt, Marianne. 1998. New Zealand English, grammar, fact or fiction? A corpus-based study in morphosyntactic variation. Amsterdam: John Benjamins.

Hupet, Michel; Michel FAyol; and Marie-AnNe Schelstraete. 1998. Effects of semantic variables on the subject-verb agreement processes in writing. British Journal of Psychology 89.59-75.

JeSPERSEn, OtTo. 1924. The philosophy of grammar. London: Allen and Unwin.

Johansson, Stig. 1979. American and British English grammar: An elicitation experiment. English Studies 60.195-215.

Joosten, Frank; Gert DeSutter; Denis Drieghe; Stefan Grondelaers; Robert J. HartSUIKer; and Dirk Speelman. 2006. Dutch collective nouns and conceptual profiling. Linguistics, to appear.

Joseph, Brian D. 1979. On the agreement of reflexive forms in English. Linguistics $17.519-23$. 
Kimball, John, and Judith Aissen. 1971. I think, you think, he think. Linguistic Inquiry $2.241-46$.

Levelt, Willem J. M. 1989. Speaking: From intention to articulation. Cambridge, MA: MIT Press.

LuCy, John A. 1992a. Grammatical categories and cognition: A case study of the linguistic relativity hypothesis. Cambridge: Cambridge University Press.

LuCy, John A. 1992b. Language diversity and thought: A reformulation of the linguistic relativity hypothesis. Cambridge: Cambridge University Press.

Mithun, MarianNe. 1988. Lexical categories and the evolution of number marking. Theoretical morphology: Approaches in modern linguistics, ed. by Michael Hammond and Michael Noonan, 211-34. San Diego: Academic Press.

Nicol, Janet L.; Kenneth I. Forster; and Csaba Veres. 1997. Subject-verb agreement processes in comprehension. Journal of Memory and Language 36.569-87.

Nixon, Graham. 1972. Corporate-concord phenomena in English. Studia Neophilologica 44.120-26.

NorRIs, DenNis. 1984. A computer-based programmable tachistoscope for non-programmers. Behavior Research Methods, Instrumentation, \& Computers 16.25-27.

Pearlmutter, Neal J.; Susan M. Garnsey; and J. Kathryn Bock. 1999. Agreement processes in sentence comprehension. Journal of Memory and Language 41.427-56.

Pollard, Carl, and Ivan A. Sag. 1994. Head-driven phrase structure grammar. Chicago: University of Chicago Press.

Quirk, Randolph; Sidney Greenbaum; Geoffrey Leech; and Jan Svartvik. 1985. A comprehensive grammar of the English language. London: Longman.

RADFORD, ANDREw. 1988. Transformational grammar: A first course. Cambridge: Cambridge University Press.

Sauerland, Uli, and Paul Elbourne. 2002. Total reconstruction, PF movement, and derivational order. Linguistic Inquiry 33.283-319.

Sмiтh, J. E. Кегтн. 1976. Data transformations in analysis of variance. Journal of Verbal Learning and Verbal Behavior 15.339-46.

Smith-Stark, T. Cedric. 1974. The plurality split. Chicago Linguistic Society 10.657-71.

Solomon, Eric S., and Neal J. Pearlmutter. 2004. Semantic integration and syntactic planning in language production. Cognitive Psychology 49.1-46.

Sparkes, Ivan George. 1985. Dictionary of collective nouns and group terms. Detroit: Gale Research Company.

Stemberger, Joseph Paul. 1992. The reliability and replicability of naturalistic speech error data: A comparison with experimentally induced errors. Experimental slips and human error: Exploring the architecture of volition, ed. by Bernard J. Baars, 195-215. New York: Plenum.

Tagliamonte, SAli. 1998. Was/were variation across the generations: View from the city of York. Language Variation and Change 10.153-91.

Thornton, Robert, and Maryellen C. MacDonald. 2003. Plausibility and grammatical agreement. Journal of Memory and Language 48.740-59.

Vigliocco, Gabriella; Brian Butterworth; and Merrill F. Garrett. 1996. Subject-verb agreement in Spanish and English: Differences in the role of conceptual constraints. Cognition 61.261-98.

Vigliocco, Gabriella; Brian Butterworth; and Carlo Semenza. 1995. Constructing subject-verb agreement in speech: The role of semantic and morphological factors. Journal of Memory and Language 34.186-215.

Vigliocco, Gabriella, and Julie Franck. 1999. When sex and syntax go hand in hand: Gender agreement in language production. Journal of Memory and Language 40.455-78.

Vigliocco, Gabriella, and Julie Franck. 2001. When sex affects syntax: Contextual influences in sentence production. Journal of Memory and Language 45.368-90.

Vigliocco, Gabriella, and Robert J. Hartsuiker. 2002. The interplay of meaning, sound, and syntax in language production. Psychological Bulletin 128.442-72.

Vigliocco, Gabriella; Robert J. Hartsuiker; Gonia Jarema; and Herman H. J. Kolk. 1996. One or more labels on the bottles? Notional concord in Dutch and French. Language and Cognitive Processes 11.407-42. 
Vigliocco, Gabriella, and Janet Nicol. 1998. Separating hierarchical relations and word order in language production: Is proximity concord syntactic or linear? Cognition 68.13-29.

Wechsler, Stephen, and Larisa Zlatić. 2003. The many faces of agreement. Stanford, CA: CSLI Publications.

Bock

Beckman Institute

University of Illinois at Urbana-Champaign

405 North Mathews

Urbana, IL 61801

[jkbock@uiuc.edu]
[Received 5 November 2004; accepted 24 June 2005] 